\title{
EL RITO FÚNEBRE MAPUCHE DEL DESCANSO: DE LA MUDA ONTOLÓGICA AL ÁRBOL DE LOS ANCESTROS
}

\author{
THE MAPUCHE FUNERAL RITE OF DESCANSO (REPOSE): \\ FROM THE ONTOLOGICAL CHANGE TO THE TREE OF ANCESTORS
}

\author{
Pablo Rojas Bahamonde 1
}

\begin{abstract}
El propósito de este trabajo es comprender el rito fúnebre mapuche del descanso desde una perspectiva ontológica y ritual. A partir de materiales etnográficos obtenidos entre 2010 y 2015 en cuatro comunidades mapuche de la comuna de Panguipulli (Región de Los Ríos de Chile), se desarrolla un análisis relevando el papel conspicuo de los ancestros (alwe) y el carácter procesual de la experiencia mortuoria en el mundo mapuche. Considerando el discurso exhortativo (amulpüllün) y el sacrificio de un ave (kare kare) realizados en el rito, se argumenta que mediante su ejecución se produce una "muda ontológica" en el püllü (espíritu) del difunto. Respecto de las materialidades asociadas al rito -denominadas igualmente descanso y cuyo referente último lo constituye un árbol-, luego de atender a las relaciones entre humanos, y entre humanos y no humanos que suscitan, se plantea su carácter de morada del pülliü en su regreso al colectivo como ancestro.
\end{abstract}

Palabras claves: descanso, rito fúnebre, mapuche, etnografía, Panguipulli.

The aim of this research is to comprehend the Mapuche funeral rite of descanso (rest) from an ontological and ritual perspective. Based on ethnographic materials obtained between the 2010 and 2015 from four Mapuche communities in the Panguipulli county (Los Ríos Region, Chile), an analysis is developed concerning the eminent role played by the ancestors (alwe) and the procedural features of the mortuary experience in the Mapuche world. Considering the exhortative discourse (amulpüllün) and the sacrifice of a bird (kare kare) performed in the rite, it is argued that by means of its realization an "ontological change" takes place in the püllü (spirit) of the deceased. In respect of the material aspects associated to the rite-equally named as descanso (repose) and whose ultimate precedent is a tree-, and then attending to the relationships between human beings, and between humans and non humans that arise, the dwelling characteristic of the püllü is contemplated on its return to the group as an ancestor.

Key words: descanso (repose), funeral rite, Mapuche, ethnography, Panguipulli.

El descanso es un rito fúnebre mapuche ampliamente practicado en la zona cordillerana y precordillerana de la Región de Los Ríos de Chile. Su ejecución se efectúa luego del velorio y antes del traslado del ataúd al cementerio para el entierro. Es fruto de una ceremonia en donde participan humanos (autoridades ancestrales mapuche, la familia y la comunidad del difunto, y las comunidades vecinas) y no humanos (antepasados) $^{1}$. Su materialidad -denominada igualmente descanso- se expresa en un altar (generalmente una cruz y/o una pequeña casa de madera y zinc), ubicado a metros de la vivienda en donde se lleva a cabo el velorio y al pie de un árbol; lugar donde se deposita el ataúd el tiempo en que se desarrollan las acciones principales del rito: un discurso al püll $\ddot{u}^{2}$ (espíritu) del difunto con objeto de propiciar su separación del plano de los humanos y una ofrenda sacrificial (kare kare) destinada a coadyuvar su agregación al plano de los alwe $^{3}$ (antepasados). El árbol, en tanto, con el tiempo, se transforma en la referencia principal del difunto, pues se convierte en morada de su püllü.

Las aproximaciones interpretativas ${ }^{4}$ al descanso poseen reciente data y se han abocado, principalmente, a su dimensión espacial y material. Así, se le ha señalado como "un hito que señala el límite de abandono del espacio cotidiano en la partida hacia lo numinoso" (Alvarado y Mera 2004:560); como una "réplica, imitación o representación de la casa en que habitó el muerto... [que] en cierto modo engaña al espíritu del difunto, evitándose sus incursiones dentro del espacio cotidiano" (Skewes, Poblete et al. 2011:9); como un altar erigido con el fin de "recordar a la persona, a quien se le ofrecen flores y se le visita para el día de los muertos o bien cuando

1 Facultad de Filosofía y Humanidades, Universidad Austral de Chile. Casilla 567, Valdivia, Chile. pablorojasbahamonde@gmail.com 
ella aparece en sueños reclamando su memoria" (Guerra y Skewes 2013:451) y como una "parte de la memoria ambiental de la comunidad" (Skewes y Guerra 2015:205) $)^{5}$. La lectura de la dimensión ritual del descanso, en tanto, se ha abocado a delinear su carácter discursivo y desvinculante. De esta forma, se ha referido la similitud con el amulpüllün de las palabras proferidas en su despliegue (Rojas 2012; Skewes, Poblete et al. 2011) y la impronta global de su ejecución, en la que se explicita, "al menos en el sentido que van Gennep da a los ritos, un elemento de separación" (Skewes, Poblete et al. 2011:8).

El presente trabajo se aboca a la comprensión del rito fúnebre mapuche del descanso. Para ello, se inquiere en aspectos decisivos tratados de manera exigua en abordajes previos al fenómeno; estos se refieren a la escasa importancia otorgada a entidades no humanas erigidas en sujeto ${ }^{6}$ en la ontología mapuche, y a la disgregación y atomización con que se han abordado sus dos dimensiones: el rito y la materialidad subsecuente.

\section{Supuestos Teóricos}

La perspectiva teórica de gran alcance suscrita se nutre de propuestas recientes dentro del campo de la antropología encasilladas bajo el rótulo de "giro ontológico" (González 2015; Henare et al. 2007; Holbraad 2010, 2014; Viveiros de Castro 1996) ${ }^{7}$. El modo en que se asume esta perspectiva es mediante tres supuestos. Primero se entienden las ontologías, en plural, como los "sistemas de propiedades atribuidas a los existentes que sirven de punto de anclaje a formas contrastadas de cosmologías, modelos de lazo social y teorías de la identidad y la alteridad" (Descola 2012 [2005]:190). La ontología moderna o "naturalismo" (Descola 2012 [2005]), caracterizada por una "gran división" (Latour 2007 [1991]) entre los dominios de la naturaleza y la cultura, se sitúa como una posibilidad, entre otras, de asignarle propiedades y distribuir a los existentes en el mundo. De tal manera, asumiendo este aserto, el universo troca en un "pluriverso" (Escobar 2012, 2014) y la ontología dualista occidental da paso a la visibilización de "ontologías relacionales" (Blaser y de la Cadena 2009) en las cuales 'lo social' se extiende en dominios donde se encuentran un conjunto de entidades no humanas, las que desde el naturalismo son conceptualizadas como pertenecientes a un mero dominio pasivo y homogéneo, ubicado dentro del plano de la naturaleza ${ }^{8}$.
Segundo, a partir de las implicancias aparejadas a la constatación de la existencia de ontologías distintas a la occidental o naturalista, es posible atender distintos ámbitos y niveles. Uno de ellos es el plano epistemológico. Y desde allí, consecuentemente,
si se admite que la distribución de las propiedades de los existentes varía de acuerdo con los modos de identificación [...] también habrá que admitir que varían en una misma medida los regímenes de conocimiento, las posiciones epistémicas que los hacen posibles y la manera resultante de tratar un problema (Descola 2012 [2005]:480).

Siguiendo la propuesta del geógrafo Turnbull (2000), quien plantea que todo sistema de conocimiento es local y posible de distinguirse de otros por el modo de ensamblaje que ejecuta, se puede trazar la singularidad de la epistemología naturalista. Esto, debido a la profusión de epistemologías indígenas documentadas en donde los ámbitos que proveen un conocimiento válido, así como las entidades capaces de constituirse en sujetos cognoscentes, disuelven los presupuestos epistemológicos del naturalismo (Århem 1993; Cruikshank 2005; Descola 2005 [1993]; Gusinde 1982 [1931]; Hallowell 1960; Kohn 2013; Leenhardt 1997 [1947]; Sahlins 2011 [2008]; Tola 2012; Vilaça 2005; Viveiros de Castro 1996, 2004, 2010 [2009]). A modo de ilustración, la epistemología mapuche es elocuente. Por una parte, ámbitos como el mundo onírico, en donde los humanos experimentan pewma (sueño), proveen un saber ${ }^{9}$ legítimo y confiable (Hirt 2012; Nakashima 1989, 1992) ${ }^{10}$. Por otra parte, los antepasados y entidades no humanas asociadas a cerros, volcanes, piedras, bosques y lagos se erigen en sujetos cognoscentes, situados de manera relacional respecto de los humanos (Alonqueo 1979; Carrasco 1986; Course 2011; Dillehay 2007; Faron 1997 [1964]; Foerster 1985, 1993; Gissi 1997; Grebe 1986, 1992, 1993-1994; Kuramochi y Nass 1991; Montecino 1997; Mellado 2014; Moulian 2012; Moulian y Espinoza 2014; Ramos 2008, 2010; Rojas 2012, 2013; Schindler y Schindler 2011).

En tercer término se ubica la crítica del concepto de cultura. Reveladora y pertinente es la lectura que Escobar (2012) desarrolla para 
entender el quiebre introducido por las propuestas de corte ontológico ${ }^{11}$. El autor operacionaliza dos definiciones de cultura para marcar la inflexión ejecutada. Por una parte, la aún dominante noción de cultura entendida como una "estructura simbólica", cuyo epítome lo constituye la propuesta semiótica del antropólogo estadounidense Clifford Geertz, ilustrada en el título de su paradigmático libro $\mathrm{La}$ Interpretación de las Culturas (2005 [1973]) ${ }^{12}$. Esta conceptualización se encuentra anclada al naturalismo e implica una consideración dualista en donde se ubican "los procesos culturales como existiendo en un dominio autocontenido ('la cultura', 'lo cultural'), con relación a 'lo material' y a 'la realidad', pero siempre en una posición secundaria a estas" (Escobar, 2012:9). Además, se relaciona exclusivamente al dominio de los humanos -en contraste con los no humanos-, citándola, en no pocos casos, como su marca identitaria distintiva. Por otra parte, las propuestas de los trabajos de corte ontológico vehiculan una noción de cultura como "diferencia radical", la cual,

partiendo de otras premisas ontológicas que cuestionan los dualismos constitutivos de las formas dominantes de modernidad (sujeto/ objeto, naturaleza/cultura, civilizados/ no civilizados, humano/no humano, etc.) [...] postulan la diferencia radical entre mundos, los cuales están, sin embargo, interrelacionados (Escobar 2012:8).

La perspectiva de alcance medio adoptada en este trabajo se ubica dentro el campo de los estudios rituales en antropología, y corresponde a aquella tradición que concibe los ritos como instancias eminentemente integradoras y de sedimentación de vínculos colectivos (Durkheim 2012 [1912]; Smith 1956 [1889]; van Gennep 2008 [1909]). Inserto dentro de esta tradición es que el etnólogo francés Robert Hertz se aboca a los ritos fúnebres en su clásico texto Contribución a un estudio sobre la representación colectiva de la muerte (1990 [1907]). Más allá de los detalles formales en su indagación acerca de las dobles exequias, la relevancia actual de la propuesta de Hertz es que sitúa a los ritos fúnebres como mecanismos en donde determinados miembros fallecidos de un colectivo son transformados ontológicamente $\mathrm{y}$, luego de ello, son reincorporados al mismo en calidad de ancestros.

\section{Metodología de la Investigación}

El trabajo se posiciona desde un paradigma de corte comprensivo (Sautu et al. 2005); la metodología posee un carácter cualitativo (Taylor y Bogdan 1994 [1984]; Vela Peón 2001). La estrategia metodológica corresponde a la etnografía, concebida como un proceso interesado, reflexivo y consciente destinado a la producción de conocimiento desde una perspectiva antropológica. El trabajo de campo se desarrolló en el área cordillerana de la comuna de Panguipulli, Región de Los Ríos, Chile. Específicamente, en las comunidades Juan Quintumán, Inalafquén y Valeriano Cayicul del sector lago Neltume; y la comunidad Manuel Curilef del sector Punahue ${ }^{13}$ (Figura 1) ${ }^{14}$. La duración del trabajo de campo se extendió -compuesto por visitas cortas de días, a estancias amplias de meses ${ }^{15}-$ de abril de 2010 a noviembre de 2015 e incluyó 38 entrevistas en profundidad, cuyo requisito fue el que en ellas participaran personas que hubieran concurrido a, por lo menos, tres ritos de descanso y que contaran en los límites del predio de su vivienda con, por lo menos, un descanso (en su dimensión material); 20 entrevistas focalizadas, en donde se escogieron personas con un acercamiento privilegiado a la temática (por ejemplo, ejecutantes del rito y/o sus ayudantes) con objeto de indagar aspectos problemáticos y/o ambiguos; observación participante, cuyos "escenarios" (Guasch 2002 [1997]) más relevantes fueron la asistencia a cuatro funerales y el acompañamiento a los sitios de descanso pertenecientes a cada uno de los entrevistados; observación focalizada, desplegada fundamentalmente en las instancias precedentes y con el objeto de esclarecer aspectos oscuros y verificar prácticas estructurales; registro fotográfico, escrito y de audio, utilizado con la intención de plasmar la información a ser analizada; por último, registro audiovisual, con el cual se efectuó "observación directa reconstructiva" (Rojas et al. 2015), "observación diferida" (Guarini 1991) y "observación diferida compartida" (De France 1982). Igualmente, el registro audiovisual permitió la construcción de un documental etnográfico (Rojas 2013), el que se constituyó como uno de los productos destinados a la vuelta de mano para las personas de las comunidades que participaron en la investigación ${ }^{16}$.

A continuación se refieren antecedentes de la muerte y los ritos fúnebres en el mundo mapuche, 


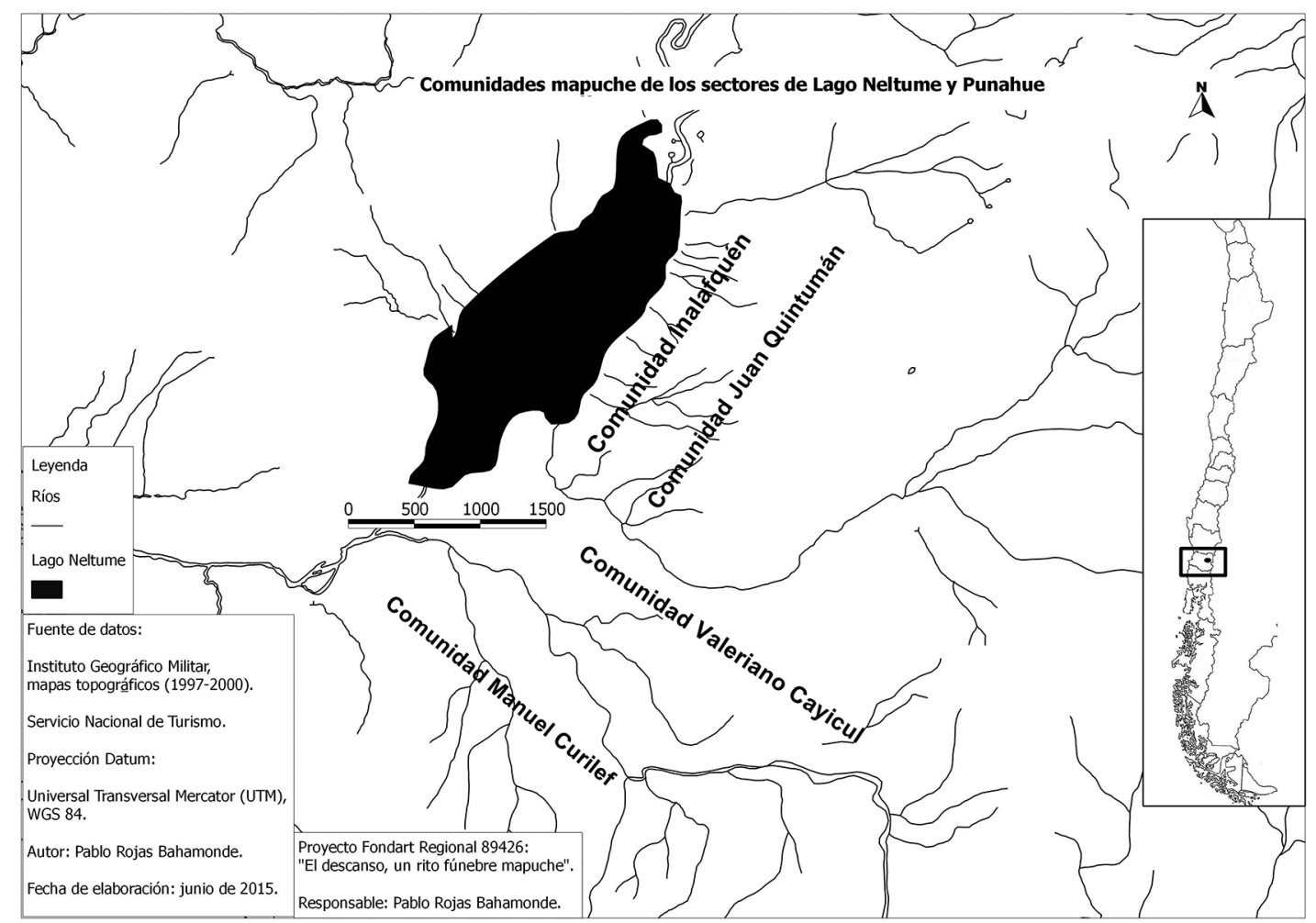

Figura 1. Mapa de las comunidades mapuche ubicadas en los sectores de lago Neltume y Punahue (comuna de Panguipulli, Región de Los Ríos, Chile).

Map of the Mapuche communities located in the areas of Lago Neltume and Punahue (Panguipulli, Los Ríos Region, Chile).

así como del rito del amulpüllün. Luego se da paso a la exposición de los resultados del trabajo de campo, divididos en tres partes. Primero, se exponen las distintas fases que componen el proceso mortuorio en el mundo mapuche cordillerano. Posteriormente se profundiza en el rito del descanso, proponiendo el concepto de "muda ontológica". En un tercer momento, se atiende al descanso en tanto materialidad, relevando la importancia del árbol asociado al rito. Las conclusiones, para finalizar, sintetizan los principales lineamientos expuestos e indican los aportes de la perspectiva suscrita.

$\mathrm{El}$ argumento que se propone enfatiza el papel conspicuo de los antepasados en la ontología mapuche y el marco global del proceso mortuorio en el cual se insertan los descansos (en cuanto rito y materialidad), y se sintetiza en las siguientes tres tesis: (i) Los funerales en el mundo mapuche se desarrollan con objeto de incorporar al püllü (espíritu) del difunto desde otro plano ontológico al colectivo, es decir, convertido en un ancestro ${ }^{17}$. (ii) El descanso -en tanto rito- es el momento, dentro de los funerales, en que se lleva a cabo una “muda ontológica” en el püllü del difunto, por cuanto mediante un discurso exhortativo (amulpüllün) se lo desvincula del plano de los humanos y, posteriormente, con el sacrificio de una gallina ritual (kare kare) se lo vincula al plano de los alwe o antepasados. (iii) El descanso -en tanto materialidad- informa la finalización de los funerales, al cambiar el estatuto ontológico del árbol a cuyos pies se ejecuta el rito homónimo, una vez que le sirve de morada al püllü del difunto transmutado en ancestro.

\section{Muerte, Ritos Fúnebres y Amulpüllün}

\section{La muerte en el mundo mapuche}

La experiencia mortuoria en el mundo mapuche se configura como un terreno vasto y complejo. Mas, hay ciertas ideas fuerza que se reiteran en las referencias de los trabajos respecto de la temática. En concreto, cuatro son las ideas por las cuales se puede desplegar una aproximación 
y delinear su textura. Primero, la muerte como un hecho no natural. En el mundo mapuche "no hay muerte natural" (Foerster 1993:90; Pérez y Lucena 2000:268). La cesación de la vida es experimentada como fruto de una intencionalidad externa a la persona. De esta manera, independiente de las características del difunto (ya sea avanzada edad o sufrir algún tipo de enfermedad), la causa de su muerte siempre es atribuida a la voluntad de un agente específico, generalmente un kalku (brujo). Así, la muerte de una persona trae aparejada la búsqueda de la persona causante de ella. Segundo, la muerte como separación de distintos componentes del ser. La muerte involucra la separación de los distintos elementos constitutivos de la persona. $\mathrm{Si}$ bien no existe unanimidad en cuanto a su número y su carácter específico dentro de la existencia de la persona mapuche -varía dependiendo del área geográfica cubierta por una determinada investigación-, son tres los elementos de mayor referencia en la literatura: el alwe, el am y el püllü (Alonqueo 1979; Barreto 1996; Bonelli 2012; Citarella 2000 [1995]; Course 2007, 2011; Foerster 1993; Latcham 1924). Tercero, la muerte como un proceso. "La muerte no es considerada como una transformación rápida" (Faron 1997 [1964]:82). Es decir, la muerte es concebida como una transición, en ningún caso como un corte abrupto y dicotómico (Latcham 1924). Cuarto, la muerte como un umbral escatológico. Desprendida de la idea anterior, la muerte igualmente se yergue como un umbral, cuyo cruce sitúa al difunto en otro plano de existencia (Véliz 1996). Al respecto, ya a principios del siglo XX, Guevara afirmaba que

poco han variado [...] las ideas del indio acerca de las vida de ultratumba. Persiste su creencia en el viaje de las almas a la tierra de los muertos, de su ubicación al otro lado del mar, hacia el poniente, i de la reproducción de los actos de esta vida en la otra (Guevara 1913:259).

No obstante el lugar referido en la cita precedente, el repertorio de sitios no es unívoco. De tal modo, autoras como Mayo Calvo (1990 [1968]) y Grebe (1986) ubican al volcán como posible morada postmortuoria del püllü del difunto, Curaqueo (1989-1990) y Montecino (1997) citan un cuerpo de agua que debe ser vadeado, y Schindler (1996) da cuenta del cénit como lugar de llegada.

\section{Ritos fúnebres}

Los ritos fúnebres mapuche se erigen como prácticas centradas en la gestión empírica de los aspectos vehiculados en las ideas anteriores. En ese sentido es que Faron apunta que "el funeral es un estado de transición para el difunto y al manejarlo de forma adecuada es un paso hacia el descanso eterno en el más allá" (Faron 1997 [1964]:82). Siendo más específico, Foerster plantea que el rito funerario "tiene como fin asegurar que el pellu tenga un viaje sin dificultad a la tierra de arriba" (Foerster 1992:24). El fin último, en tanto, se ubica en convertir al difunto en un ancestro, el que una vez acaecida la transformación se erige como una figura mediadora entre diversos planos ontológicos (humanos-no humanos), debido a que, al mismo tiempo, "participa de la condición 'sagrada' como de la humana" (Foerster 1992:25) ${ }^{18}$.

\section{Amulpüllün}

El amulpüllün es un rito funerario mapuche destinado a propiciar un correcto tránsito del pülliü desde el plano de los humanos (Schindler 1996). En lo esencial, corresponde a palabras emitidas en idioma mapudungun por una (Bacigalupo 2008-2009; Caniguan y Villarroel 2011; Jara et al. 1980; Rojas et al. 2011; Rojas 2013) o más personas (Coña 1971 [1930]; Curaqueo 1989-1990; Course 2011; Faron 1997 [1964]; Kuramochi y Huisca 1997; Schindler 1996; Stuchlik 1999 [1976]; Titiev 1951), definidas de antemano para la ocasión, centradas en la persona fallecida, ya sea de manera directa, mediante un discurso exhortativo (Bacigalupo 2008-2009; Coña 1971 [1930]; Curaqueo 1989-1990; Jara et al. 1980; Kuramochi y Huisca 1997; Rojas et al. 2011; Rojas 2013; Schindler 1996) o indirectamente, por medio de referencias biográficas y/o genealógicas (Caniguan y Villarroel 2011; Course 2011; Faron 1997 [1964]; Stuchlik 1999 [1976]; Titiev 1951). Si bien ya en el siglo XVII De Ovalle (2003 [1646]:162) cita "un funesto y triste canto" en el contexto de los funerales de una persona mapuche, quizás el antecedente más importante del amulpüllün, en cuanto a profundidad histórica, contenido ritual y área geográfica de ejecución (respecto de este trabajo), lo constituyen las referencias del naturalista francés Claudio Gay, quien entre 1835 y 1836 viajó por las provincias de Valdivia, Osorno y Chiloé. Justamente, en el marco de ese periplo, el investigador tuvo la ocasión 
de participar en la ceremonia fúnebre ofrecida en honor a un fallecido jefe mapuche llamado Cathiji, efectuada en el sector de Guanegüe, adyacente al lago Panguipulli (Figura 2). En su relato del funeral, el naturalista cita en variadas oportunidades, además de trillas en torno al ataúd "compuesto de dos canoas colocadas la una sobre la otra" (Gay 1998 [1844]:21), "esas especies de cuyuntucus o discursos cadenciosos que dos interlocutores se dirigen recíprocamente y que tenía por objeto hacer resaltar las bellas cualidades de la persona a quien iba dirigida" (Gay 1998 [1844]:21). El otro aspecto relevante, anejo a la oratoria, es la cantidad ingente de sacrificios ejecutados. Apunta al respecto Gay que "en menos de dos horas, habían sido inmolados más de cuarenta animales en honor de Cathiji" (Gay 1998 [1844]:22).

\section{Hallazgos de Campo}

\section{Proceso mortuorio}

El descanso se ubica dentro del proceso en que se configura la muerte en el mundo mapuche cordillerano. La muerte, de tal manera, refiere a una experiencia que se despliega en varias fases y etapas. Los distintos eslabones acaecen en una sucesión que impide circunscribir la muerte a un momento concreto, objetivo, universal y homogéneo para la totalidad de las personas. Así, y a diferencia de la muerte actual en el mundo chileno (permeada por el discurso biomédico y, por tanto, igualada a la "muerte clínica"19), la muerte de una persona puede comenzar antes del cese de sus funciones vitales corporales y extenderse posterior a estas.

En las comunidades mapuches de lago Neltume y Punahue la muerte es un hecho eminentemente moral. Es decir, la muerte de una persona está sujeta, y sujetada, a las acciones que emprende y su correspondencia, o no, respecto de las normas establecidas ( $A d M a p u)$. El momento en que la vida de una persona queda signada por la muerte se encuentra en correlación a la transgresión del código moral fijado en las comunidades. De tal manera, el detonante del proceso mortuorio es siempre ubicuo, contingente y singular a cada persona.

Los actos convertidos en transgresiones de carácter mortal se encuentran asociados, en la mayoría

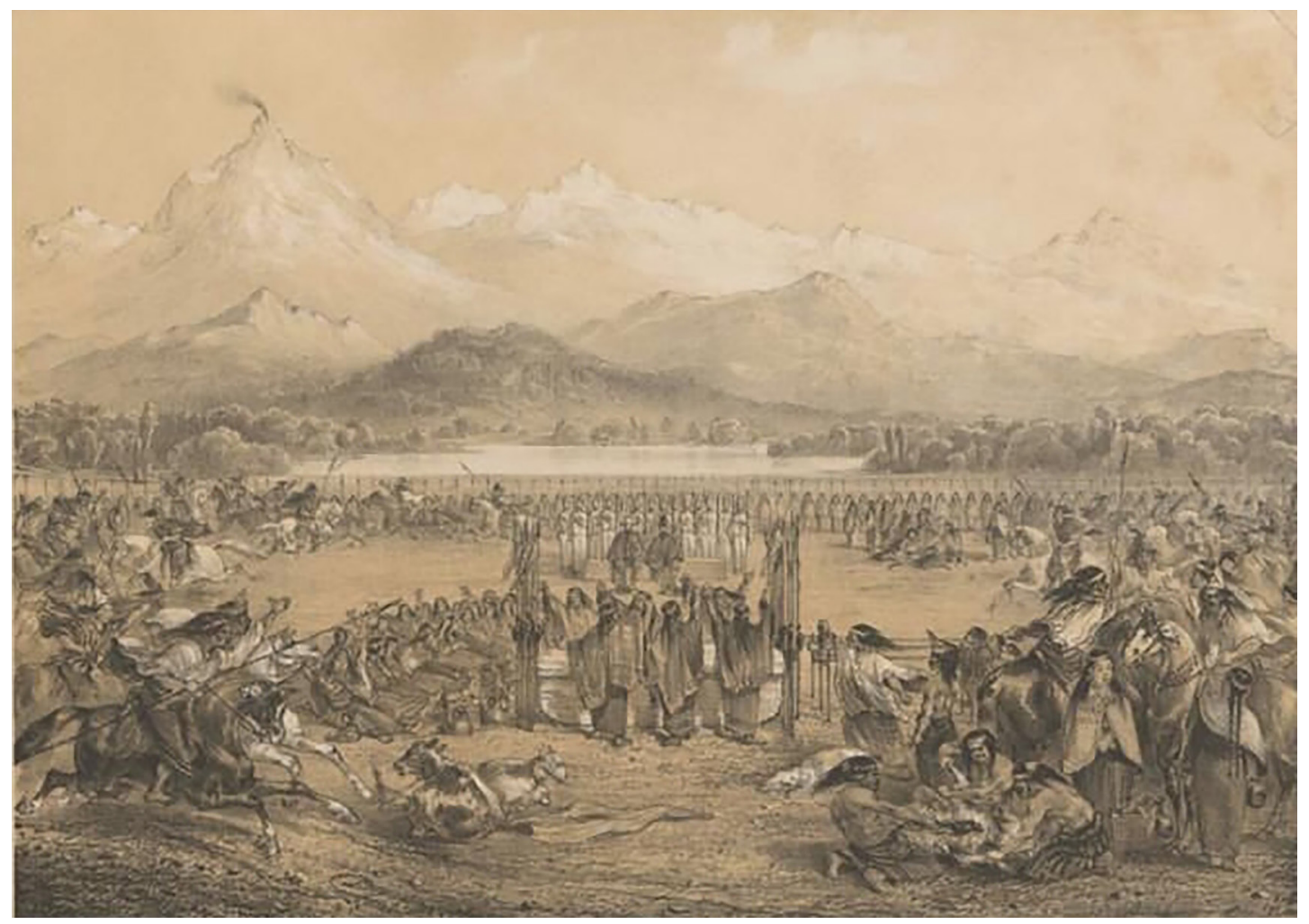

Figura 2. Entierro del Cacique Cathiji en Guanegüe, mayo 1835. Fuente: Gay (2010 [1854]).

Burial of Cacique Cathiji in Guanegüe, May 1835. Source: Gay (2010 [1854]). 
de las ocasiones, a actos incorrectos ejecutados en ritos y en espacios en donde se hacen presentes entidades no humanas ${ }^{20}$. En la ceremonia del Ngillatun es posible cruzar un umbral que detone la infiltración de la muerte en la vida de una persona. El Ngillatun es quizá el momento que mayor densidad experiencial suscita dentro de la vida mapuche. Se dan cita en él, con objeto de regular sus relaciones, diversos sujetos no humanos, como los ngen, Ngenechen y los alwe; y humanos, correspondientes a las comunidades que conforman la congregación ritual, tierras aliadas o wichan mapu (comunidades Juan Quintumán, Inalafquén y Valeriano Cayicul), además de invitados de comunidades y sectores aledaños. Proverbial en el sector es la historia de Eduardo Q. Se recuerda su muerte por un infarto cardíaco, fruto de haber proferido insultos en el contexto de la citada ceremonia.

Una incorrecta relación con los seres denominados ngen también puede dar paso al proceso mortuorio. Los ngen corresponden a los dueños, cuidadores y dominadores de un espacio específico, siendo a su vez relacionados a elementos naturales presentes en el mismo. Los ngen más referidos en el área, quizá por la regularidad y cotidianidad con que las personas se internan en sus dominios, son el ngen co y, sobre todo, los ngen relacionados con cerros y montañas: ngen mawiza, ngen wingkul y ngen тари. De tal manera, frente a cualquier incursión en la montaña, y debido a la presencia de los dueños mencionados, los humanos deben cumplir con un estricto repertorio de acciones. El repertorio incluye no elevar el volumen de la voz, abstenerse de proferir insultos y de hacer destrozos innecesarios y, en caso de usufructuar de algún elemento, conviene -a manera de propiciación- realizar una oración breve (ngellipun), la que puede incluir muday (bebida ritual a base de trigo $)^{21}$, ofrendas como pan y trozos de carne cocida sin sal y, eventualmente, animales menores destinados al sacrificio, como gallinas. La infracción de cualquiera de las normas mencionadas por parte de las personas, abre la posibilidad de que el ngen se sitúe en una actitud beligerante. El procedimiento de castigo más usual y que más se menciona es la aparición de una espesa niebla, la cual desorienta a las personas y las puede llevar a perderse horas, días, e incluso varias semanas, haciendo peligrar su vida. En faltas más extremas, como apropiarse de elementos ubicados en el nicho del ngen o avistarlo directamente, este puede actuar directamente, produciendo enfermedades o accidentes, factibles de provocar el deceso inmediato de la persona afectada.

El reconocimiento de la acción de entidades no humanas, por cierto, no excluye el reconocimiento de enfermedades propias de la taxonomía médica oficial que puedan afectar y deteriorar a una persona causándole la muerte. De hecho, la totalidad de personas que durante mi estadía fallecieron en el sector en algún momento fueron hospitalizadas en Panguipulli, y, posteriormente, en Valdivia al agravarse, y su diagnóstico médico fue aceptado sin equívoco por el enfermo y sus respectivos familiares. No obstante, la causa última atribuida a la aparición de la enfermedad, su intensidad y su posterior muerte, se asociaba a algún tipo de contravención 22 .

El deceso del cuerpo marca el inicio de los funerales. El cuerpo, convertido en cadáver, se configura como detonador de diversas prácticas rituales por parte de las personas de las comunidades. Estas se encuentran en un continuum cuyo sentido es el incorporar al fallecido como ancestro al colectivo. A continuación, y para efectos analíticos, se presentan de manera esquemática estos actos.

\section{Deceso}

El deceso del cuerpo de una persona es seguida por la difusión de la noticia. Una o más personas cercanas al difunto se erigen en werken, es decir, mensajeros. Estos comunican el fallecimiento en la comunidad y en las comunidades vecinas. Además de la divulgación de la noticia, la muerte de una persona conlleva la preparación del cuerpo y del espacio para el desarrollo del velorio. La realización de estas tareas corresponde generalmente a las mujeres parientes del difunto y/o al personal de la funeraria local ${ }^{23}$. El espacio para la realización del velorio, en tanto, se determina en función de su capacidad para acoger de la mejor manera a las diversas personas que se darán cita. Así, en la práctica, salvo excepciones, el lugar en donde se ubica el ataúd es el living-comedor, el cual es el espacio más amplio de las casas en las comunidades ${ }^{24}$. Un aspecto remarcable de señalar es la importancia atribuida a la realización de los funerales en la casa del difunto. Independientemente del lugar en donde se haya producido la muerte y/o donde haya estado viviendo, es condición insoslayable que el cuerpo sea trasladado a su lugar de origen. El porqué de la importancia del traslado del difunto a su tuwün 
o lugar de origen se relaciona directamente con el carácter decisivo que tiene la correcta realización de funerales para el devenir del püllü del difunto.

\section{Velorio}

El velorio corresponde a una instancia de encuentro, en donde las diversas personas que conocieron al difunto asisten para despedirlo y, de igual manera, acompañar a los familiares del mismo. Comienza una vez que se encuentra dispuesto el ataúd y el mobiliario en la sala. Sillas y bancos (muchos construidos exclusivamente para la ocasión) se colocan en rededor, pegados a las murallas de la sala, para acoger a los visitantes que a toda hora se harán presentes. Un aspecto fundamental del velorio es la hospitalidad brindada a cada visitante; la forma predominante en que se expresa es por medio del alimento. Como me aclaró en el funeral de su esposo la señora Rosario Q. de la comunidad Juan Quintumán: "Lo más importante es que nadie se puede quedar sin comer". Para esos efectos se destinan vacunos (uno o dos por lo general), ensaladas (donde no faltan papas y tomate con cebolla) y un vaso de vino tinto; ello constituye el plato principal. Por otra parte, mate, pan, sopaipillas ${ }^{25}$ y vino tinto circulan asiduamente durante el transcurso del día. El alimento no se circunscribe solo a los humanos; también al difunto le es depositada una ración: un vaso de vino tinto y un trozo de carne sin sal ubicados a los costados del ataúd. El velorio mapuche constituye la última instancia de vínculo en un mismo plano entre el difunto y los humanos. Es un momento de congregación con el difunto vehiculizado por la consumición grupal de los alimentos. Este carácter vinculante de los alimentos queda subrayado por medio de una regla negativa: "los animales del velorio se tienen que ir enteros, no puede quedar nada de comida" (Juana R.).

\section{Descanso}

El descanso es un rito que se desarrolla en el intervalo de tiempo que media entre el fin del velorio y el entierro. La relevancia que posee en el marco del proceso mortuorio mapuche es que es el primer momento en que el espíritu del difunto se transporta a otro plano ontológico. Su duración es de quince a treinta minutos aproximadamente. Consiste en el traslado del ataúd desde la sala del velorio hacia un lugar, escogido de antemano, cuyos requisitos son el que se emplace dentro de los límites prediales de la vivienda del difunto, haya sido del gusto de este y en cuya cercanía se alce un árbol. Además, la erección de un descanso con anterioridad, marca igualmente la elección del sitio. En el lugar determinado se conforma en semicírculo una congregación ritual, comandada por un orador situado frente al ataúd que se posa en el suelo. El orador es un hombre anciano de la comunidad, generalmente investido de un cargo tradicional que -pertrechado de un cigarro y un vaso de raulí colmado de muday- lleva a cabo un discurso al püllü (espíritu) del difunto con el fin de separarlo del plano de los che o humanos. Este puede tomar un carácter adusto o afable. El primer viso caracterizó la exhortación al espíritu de la madre de María P. de la comunidad Juan Quintumán, quien cita algunas de las frases emitidas en aquella ocasión:

Yoz wüño welaymi [No vuelvas más]/ Amutuimy [Ya te fuiste]/ Wiño melaymi pu familia meo [No vuelvas a la familia]/ Piñenmeo wentru piñen domo piñen [No vuelvas por tus hijos, por tus hijos hombres y tus hijas mujeres] ${ }^{26}$.

El segundo talante, más amable, es el que alude el longko de la comunidad mencionada: "Ahí [en el descanso] se le dice que dejó de existir, que ya se va a entregar a nuestra ñuke mapu [madre tierra] y que están los que fueron antes y que ahí se va a ir a presentar" (José C.).

Sumado a los discursos, y con objeto de propiciar la incorporación del espíritu del difunto ahora al plano de los alwe o antepasados, se destina como sacrificio un animal. Este corresponde a una gallina, la cual se denomina kare kare y es escogida de acuerdo con tres condiciones. Primero, tiene que presentar un estado óptimo, esto se entiende como un animal ausente de marcas, problemas de salud o discapacidades físicas; luego, su color, el que debe ser "ceniza o neblino, como el cuerpo del volcán Mocho [Choshuenco]" (René P.) o amarillo27; por último, la forma, quedando descartadas las de 'cuello pelado', "porque son disparejas y no son tan bonitas como las otras, las con cuello parejito; y obvio que uno va a querer entregarle lo mejor a los antiguos" (Erwin Q.). Al final del discurso exhortativo el orador puede esclarecer al püllü del difunto (y al lector) la función vinculante del 
sacrificio, intercalando frases -al tiempo que levanta el ave con su diestra- como las siguientes:

Kümey ngyual tuaymi [Te mando con esto para que te vaya bien]/ Lletuan mi rokin chalin tuku putuaymi, cheo mi pun alwe meo/ [Lleva esta comida para que llegues bien donde te vayas a presentar, donde los que se fueron antes] $]^{28}$ (Teresa T.)

Además de la presentación oral del kare kare al püllü del difunto, el orador puede enquistarle mensajes de cortesía en su cuerpo, aumentando la posibilidad de que sea bien recibido por las entidades no humanas a las cuales se destina. El procedimiento lo efectúa expulsando sobre la ofrenda bocanadas de humo y/o gotas de muday, acompañadas de frases en mapudungun en concomitancia con la motivación de estas acciones.

Efectuados los actos propios de la presentación y propiciación, el kare kare es decapitado por el orador, o su eventual ayudante, mediante un certero tirón. Los movimientos que en los estertores despliega son interpretados minuciosamente por el orador y seguidos con atención por los distintos participantes. Su importancia radica en que expresan la actitud del püllü del difunto ante su partida del espacio familiar. Si bien no existe una taxonomía oracular definida que puntualice los significados del desplazamiento que el kare kare moviliza en su agonía, se establece un punto de confluencia en la importancia atribuida al puel тари. Así, la situación ideal deseada por una familia corresponde a su eventual movimiento hacia el este, dirección hacia la cual igualmente esperan que apunte su cuello al fenecer.

Una vez muerto el kare kare y emitido el dictamen del orador a la familia acerca del estado del püllü de su pariente, el cuerpo es arrojado a las llamas, culminando su estatuto de sacrificio. Considerables precauciones se centran en que se consuma íntegro, sin interrupción -fundamentalmente de los perros que pululan hambrientos-, pues de lo contrario "el espíritu tiene problemas para irse, y entonces puede volver y llevarse a alguien de su parentela" (María C.). Las medidas precautorias para resguardar la consumición de la ofrenda pueden tomar variadas formas, siendo la más utilizada el emplazamiento de una persona dedicada exclusivamente a atender el discurrir del fuego hasta su extinción total. Una vez que esto ocurre, hombres de la comunidad levantan el ataúd; lo giran -preocupándose de que se vaya con los pies del fallecido hacia delante-, y emprenden la marcha al camino, hacia la carroza fúnebre que trasladará el ataúd al cementerio para el entierro.

\section{Entierro}

El entierro marca el cierre de los ritos fúnebres y se desarrolla íntegramente en el cementerio. El cementerio de Punahue es el espacio utilizado en la actualidad por los comuneros del sector de lago Neltume ${ }^{29}$, cuya distancia, en movilización, se cubre en aproximadamente quince minutos. En cada funeral, autos y buses -algunos contratados para la ocasión-trasladan a los familiares y a las personas de las comunidades. El entierro constituye el rito en donde más gente asiste. Al llegar la caravana, se traslada el ataúd a un costado de la tumba, cuyo espacio se encuentra cavado desde la mañana. El espacio se ordena con los familiares en la cabecera de la tumba, orientados hacia el puel mapu ${ }^{30}$. Se encuentran acompañados por alguna autoridad tradicional, generalmente el longko, encargado de proferir las últimas palabras, las cuales refuerzan y/o reiteran las referencias operadas en el rito del descanso. El entierro explicita la desvinculación del plano de los humanos del püllü del difunto, por cuanto diversos objetos le son suministrados -ropa, alimentos (rokin), monedas, varillas para espantar canes, cántaros (metawe), entre otros- con el fin de que sortee de forma óptima el viaje que deberá emprender. Con ese objeto, por último -y en caso de no haber sido consumidos en su totalidad los alimentos del velorio-, los familiares del difunto se instalan en un galpón expresamente levantado a un costado de la entrada del cementerio: allí sellan la despedida, comiéndose los trozos de carne sobrantes, mientras los demás asistentes inician la caminata de vuelta a sus hogares.

\section{La muda ontológica}

Un aspecto crucial del rito del descanso está dado en la capacidad performativa que posee, pues mediante las prácticas que se ejecutan se busca trasladar al püllü del difunto del plano de los humanos al plano de los antepasados. Esto se logra, principalmente, por medio de las dos prácticas centrales del rito: por una parte, el amulpüllün o discurso exhortativo con el cual se busca la desvinculación del püllü del difunto del plano de 
los che o humanos; por otra, con el sacrificio de la gallina ritual (kare kare), el cual es extendido a los alwe o antepasados con objeto de que lo integren en su plano. Importante es apuntar que de ninguna manera se plantea que el püllü del difunto se convierte ipso facto en antepasado luego del rito descanso, sino -y solo si se ejecuta de manera correcta el rito-que pasará al plano de los alwe o antepasados. Una vez allí, seguirá el entierro y luego el trayecto hacia el volcán y, eventualmente, su vuelta -ahora como antepasado- a la materialidad del descanso.

Del mismo modo en que uno de sus dos actos centrales se aboca a la vinculación con los antepasados, el rito mapuche del descanso posibilita el diálogo crítico con propuestas teóricas ancestrales dentro de los estudios rituales en antropología. Acorde con su carácter de clásico, "Los Ritos de Paso" de Van Gennep (1990 [1909]) constituye un referente que cruza el siglo XX en lo relativo al estudio de las transiciones rituales. Desde una mirada comparativista y universalista ad hoc con su contexto intelectual, dos son las ideas fuerza contenidas en la obra. La primera es la identificación de un patrón transcultural presente en los ritos de paso; la segunda es la propuesta de un esquema tripartito en que este patrón se divide y despliega: separación, ambigüedad o liminalidad y agregación son las fases señaladas por las que debe pasar un individuo en su tránsito de un estado a otro. La mención precedente es relevante, por cuanto, y a pesar de las célebres reformulaciones al esquema realizadas por Turner (1999 [1967], 1988 [1969], 1974) y Turner y Turner (1978),

los presupuestos conceptuales y principios epistémicos universalistas que manejaron Van Gennep y sus contemporáneos[...] han tendido a ser reproducidos y validados de manera relativamente acrítica por generaciones sucesivas de científicos sociales (Mondragón 2009:123).

El descanso -con sus discursos y gallinas recortando el lago Neltume- se escabulle de la fórmula canónica de los ritos de paso. $\mathrm{Si}$, por una parte, en él se moviliza un claro "paso" del espíritu desde el plano de los humanos al de los antepasados; por otra, y al tiempo que ocurre este "paso", prosigue el proceso mortuorio del cual el descanso es solo un eslabón. Mas, desde la propuesta de Van Gennep (1990 [1909]) no es posible captar adecuadamente este doble proceso. Aunque el autor justamente con objeto de comprender de mejor manera las transiciones conceptualiza los propios "ritos de paso" -además de incorporar en su modelo la dimensión procesual con la noción de "liminalidad"-, en última instancia el cambio, el "paso", posee en su modelo un carácter terminante y dicotómico (vivo/ muerto, persona/antepasado).

El desafío intelectual que el rito del descanso propone, entonces, es el de teorizar etnográficamente el campo de los estudios rituales en antropología ${ }^{31}$. Con esa intención se acuña el concepto de "muda ontológica": la "muda" 32 , por una parte, atiende el delicado y doble evento en donde -al mismo tiempose produce una inflexión radical en el espíritu del difunto y (se) prosigue una de las tantas fases que componen el proceso mortuorio (como se señaló, si bien mediante el rito del descanso pasa al plano de los antepasados, no por ello se convierte en tal); "ontológica", en tanto, adjetiva el término citado, indicando el singular cambio en el estatuto del ser del püllü del difunto -cierto, mas no concluyente-al cruzar de un plano a otro.

Mediante la propia nomenclatura de Van Gennep (1990 [1909]) se pueden ilustrar las diferencias entre los dos esquemas rituales (Figura 3). El "rito de paso" -a la izquierda de la figura- despliega las distintas fases de forma consecutiva y excluyente; el "paso", en ese marco, sella irremediablemente la posición alcanzada por el sujeto ritual. El rito del descanso -a la derecha- ordena el mosaico precedente a la mapuche: contenidos ${ }^{33}$ en el proceso mortuorio y su carácter liminal, se desarrollan los dos actos que suscitan la "muda ontológica": el discurso exhortativo que produce la desagregación del püllü del difunto del plano de los humanos y la ofrenda sacrificial que lo agrega al de los antepasados.

\section{El árbol de los ancestros}

El descanso posee una dimensión material, inextricablemente unida al rito fúnebre homónimo. Por una parte, como ya se señaló, el sitio en donde se lleva a cabo el rito fúnebre se escoge en función de determinadas características -gusto del difunto, límite del predio, presencia de un árbol ${ }^{34}$ $\mathrm{y}$, eventualmente, la presencia del descanso de un familiar-establecidas de antemano. A esos aspectos, por otra parte, se le añade la materialidad que se emplaza en el marco del rito, la que toma la forma de una cruz ubicada a los pies del árbol escogido o 


\section{Esquema rito de paso}

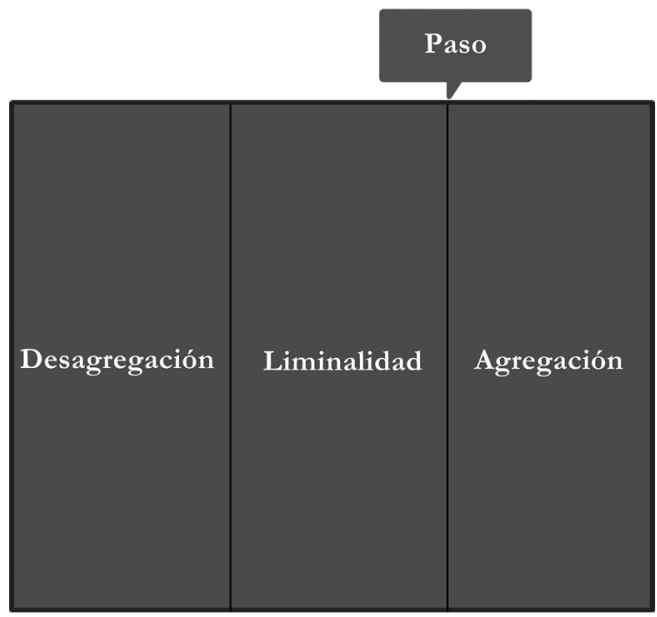

\section{Esquema rito del descanso}

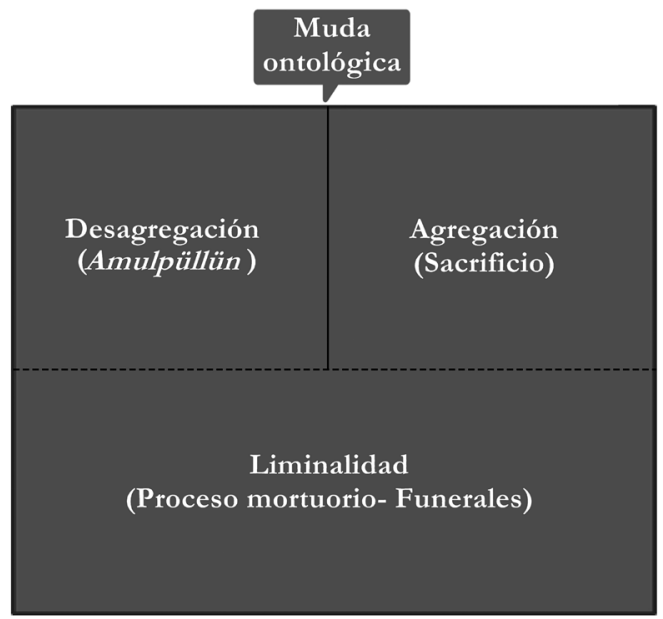

Comparación esquema rito de paso y esquema rito del descanso.

Comparison between the rite of passage diagram and the rite of repose diagram.

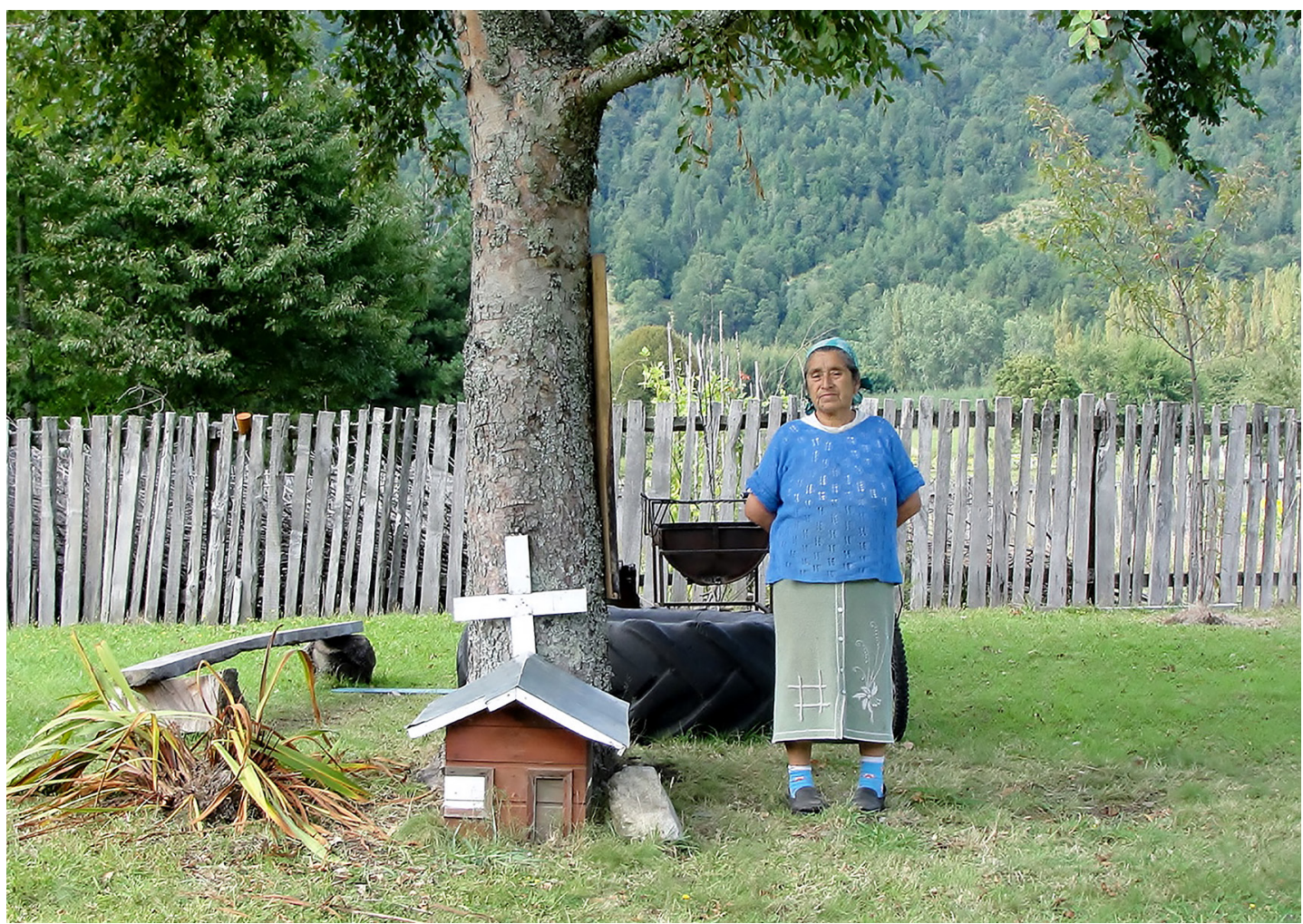

Figura 4. Rosa V. junto al descanso de su hijo emplazado a los pies de un walle (roble joven) en la comunidad Manuel Curilef de Punahue.

Rosa V. next to the descanso (repose) of her son located at the feet of a walle (young oak tree) in the community of Manuel Curilef of Punahue.

bien adyacente. Además de esta, y dependiendo del interés de los familiares, se puede erigir una pequeña vivienda, estéticamente similar a las animitas del mundo chileno ${ }^{35}$. Ese es el caso de la señora Rosa
V., de la comunidad Manuel Curilef, quien ubicó el descanso de su hijo a los pies de un walle (roble joven), en donde, junto a la cruz, construyó una pequeña vivienda (Figura 4). 
La elección y erección del descanso se relacionan estrictamente a la distancia del püllü del difunto. La selección del límite se escoge en función de posibles contagios peligrosos $\mathrm{y}$, a su vez, de la accesibilidad de los humanos respecto de él; la materialidad -principalmente, el árbol-se establece con objeto de un emplazamiento persistente en el tiempo. El prurito en el cuidado y la elección se deben a que el sitio del descanso se constituye en morada del püllü del difunto.

El püllü, de esta manera, se asocia estrechamente al descanso. No obstante, el momento en que acaece la unión no posee unanimidad de acuerdo con las versiones locales. Existen planteamientos que refieren el emplazamiento del püllü inmediatamente después de desarrollado el rito. Otras versiones plantean que el püllü se queda deambulando en el sector por un tiempo indefinido, teniendo como espacio intermitente el sitio del descanso hasta un momento en que se produce su total asentamiento. Sin embargo, la versión más extendida es aquella que plantea que el püllü se traslada hacia un determinado lugar por un tiempo para luego efectuar su regreso. Esta versión es la que posee mayor plausibilidad, debido a cinco razones. Primero, porque existen referencias explícitas del volcán como el lugar hacia donde lleva a cabo el viaje el püllü, las que son vehiculizadas por medio del pewma (sueño). Segundo, porque estas referencias se condicen con referencias espaciales de sitios significativos. Así, el cementerio de la comunidad Juan Quintumán e Inalafquén se encuentra emplazado en un espacio en donde se divisan los dos volcanes del sector -Villarrica y Mocho-Choshuenco-, además de ubicarse las tumbas mirando en dirección al área del primer volcán mencionado, y las cabeceras en dirección al segundo mirando ${ }^{36}$. El tercer punto a considerar se encuentra en los pertrechos que le son suministrados al difunto en el entierro ya tratado, los que explicitan una travesía; diferentes utensilios son depositados dentro de la tumba para dotar al püllü del difunto de lo necesario en el viaje que emprende. Cuarto, sumado a las tres pruebas citadas, igualmente el viaje del püllü queda explicitado en la ya citada ofrenda de la gallina ritual (kare kare), sacrificada posterior al amulpüllün en el marco del rito del descanso. El quinto y último elemento a considerar son las referencias concomitantes del área que sitúan a los volcanes como contenedores de los espíritus de los difuntos (Alvarado 2000; Calvo 1990 [1968];
Grebe 1986; Hilger 1957; Kuramochi y Nass 1991; Yanai 1997) o como vías de acceso al Wenu Mapu (Koessler 2006 [1962]).

En cualquier caso, el punto en donde existe total confluencia es en la cualidad del descanso para acoger al pülliü desde un determinado momento. La materialidad es la que brinda esas labores; las formas más utilizadas corresponden a las citadas cruz y, eventual, pequeña vivienda. Son esas materialidades las que se identifican como habitáculos del püllü en un primer momento. Por ello es que son reparadas o sustituidas en no pocas ocasiones por los familiares, así como cuidadas con esmero $\mathrm{y}$, con ese objeto, "incluso se le construyen rejas de madera al descanso para que los animales no entren y lo rompan" (Anselmo J.).

Mas, el árbol, con el paso del tiempo, pasa de ser un testigo taciturno en el sitio del descanso, a convertirse en el descanso propiamente tal; pasa de ser una figura periférica en relación con las materialidades construidas, a ser la principal y única figura. Este cambio se opera de forma gradual y ordinaria. El viento, el sol, la lluvia, la humedad, el musgo y el ajetreo diario son los ingredientes que van mermando las construcciones de madera y los que, a su vez, le van otorgando legitimidad al árbol. Como me comentó don Humberto M. de la comunidad Valeriano Cayicul, respecto de un roble devenido en descanso -de su padre- ubicado en la entrada de su terreno:

Después de un tiempo ya no arreglamos [con su hermano y vecino Carlos M.] la cruz ni la cambiamos. Dejamos ahí no más tranquilo el lugar. Quedó el árbol no más. Total ya se sabe que ahí está el descanso. El árbol pasó a ser el descanso. No queda nada más.

\section{¿Puede un árbol convertirse en morada de los ancestros?}

Lejos de ser una mera frase retórica, la pregunta interroga un aspecto crucial del descanso: su estatuto ontológico. Es decir, consulta si el árbol es más que un habitáculo transitorio del püllü del difunto o una señal o marca simbólica y conmemorativa del rito a cuyos pies se ejecuta, una vez que se erige sin otra materialidad en su alrededor. En suma, si el árbol devenido en descanso cambia, de igual manera, su estatuto ontológico al ser habitado por uno o más 
püllü. Dos son las prácticas y experiencias que permiten responder a lo señalado.

Primero, el árbol devenido en descanso se convierte en un lugar de culto y de vinculación entre humanos, y entre humanos y no humanos. Las personas de las comunidades de lago Neltume y Punahue realizan distintas prácticas de culto en el árbol, los que son de dos tipos. Por una parte, cultos de carácter cíclico, enmarcados en ceremonias convencionales fijadas a priori en una fecha específica. El cumpleaños y el aniversario del fallecimiento del difunto son fechas en que acaecen estos cultos. Otro momento corresponde al Día de Todos los Santos; empero, se realiza cuando, por una u otra razón, no es posible ir al cementerio. También, aunque más laxas que las anteriores, las fechas en las que se propende a reunir a la familia igualmente suscitan actos rituales en el árbol de carácter iterativo; en la práctica, el repertorio abarca las principales fechas festivas del mundo chileno (Fiestas Patrias, Navidad y Año Nuevo), así como los períodos de vacaciones y también las ceremonias mapuche del Ngillatun y de los funerales ${ }^{37}$. Son propicias estas fechas, pues los familiares que viven fuera del sector, comuna o región, cuentan con mayores posibilidades viajar a los sectores de lago Neltume o Punahue.

El otro tipo de culto que se desarrolla en el árbol es de carácter aleatorio, dependiente de las motivaciones circunstanciales de las personas. Si bien puede adoptar una impronta familiar, su despliegue es eminentemente individual. Además, la variable de género es insoslayable para delinear los énfasis que toma su ejecución. De tal forma, en el caso de las mujeres, el culto posee un cariz hospitalario y de cuidado. Su relación con el descanso es relajada y poco premeditada; cualquier caminata cercana al perímetro en donde se haya emplazado puede transformarse en una instancia de comunicación. A su vez, una de las labores que (observé) cumplen las mujeres, excluyentemente respecto de los hombres, son aquellas relacionadas con el aseo y ornato del sitio del descanso. En el caso de los hombres, en tanto, lo distintivo de su práctica es la forma terapéutica y sensoria que adopta. Su relación con el descanso atañe a malestares de corte emocional, los cuales encuentran amortiguación y sosiego mediante el diálogo con el pülliü asentado en el árbol. A ello se suma una expresividad directa hacia su materialidad (Figura 5).

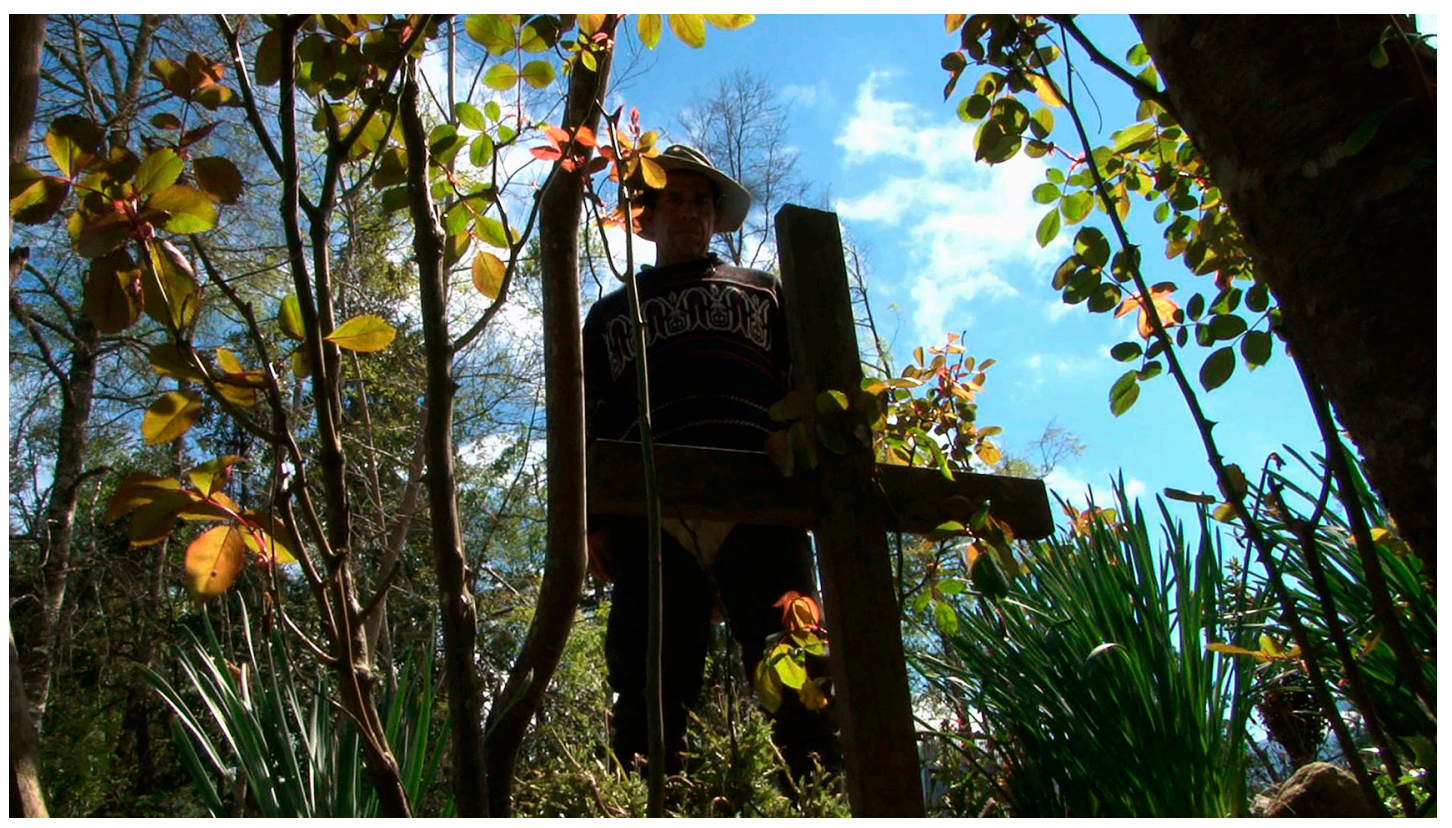

Figura 5. José D. junto al descanso de su padre emplazado a los pies de un foye (canelo) en la comunidad Inalafquén de lago Neltume. Fuente: Rojas (2013).

José D. next to the descanso (repose) of his father located at the feet of a foye (Cinnamon tree) in the community of Inalafquén of Lago Neltume. Source: Rojas (2013). 
Hay una cosa importante para nosotros. Porque ese árbol [descanso] no va a morir, va a crecer y se va a ir desarrollando. Uno cuando tiene angustia y desesperación va al árbol. Aunque uno, claro, uno tiene a la familia, pero uno se siente angustiado y puede ir a conversar y desahogarse. $\mathrm{Y}$ en ese momento es una ceremonia, porque uno está hablando con alguien vivo. Porque es una planta que está viva. Entonces eso trae un relajo, como persona me trae un relajo. El espíritu está en el árbol, porque el árbol está vivo. Para nosotros es un árbol especial, uno lo pasa a regalonear, le toca las hojas, porque el árbol está vivo (José D.).

Cualquiera sea la clase de culto establecido en el sitio del descanso, hay elementos transversales que se utilizan con el fin de propiciar y/o comunicarse con el püllü. El repertorio incluye velas, mate, vino, cerveza, agua, bebida, muday y alimentos. Salvo las velas, que son utilizadas sin distinción, la elección de los brebajes y alimentos se escoge en función del gusto del difunto.

Segundo, el árbol devenido en descanso es el principal espacio de manifestación de los alwe en el plano de los humanos. Es un espacio en donde el püllü siempre puede ser requerido. El otro espacio relevante en donde se encuentran presentes es el cementerio. Sin embargo, su presencia en este queda supeditada a fechas específicas. Una de ellas es la ceremonia que se desarrolla en vísperas del Ngillatun, denominada chalilelfun $^{38}$, cuyo despliegue tiene como objetivo pedir permiso e invitar a los antepasados a la ritualidad mencionada; otra aparición de los alwe, además de la que tienen en el ngillatuwe ${ }^{39}$, es en el marco del Día de Todos los Santos. Por último, las fechas de nacimiento y muerte del familiar señala momentos en los cuales se hace presente en el cementerio el difunto. El volcán Villarrica, en tanto, es otro de los espacios en donde se sitúan los alwe. Empero, el acceso a este hito se lleva a cabo solo por medio de la actividad onírica (pewma). El sitio del descanso, de tal manera, si bien no es el lugar excluyente en donde el antepasado se manifiesta, es el lugar en donde su presencia posee un cariz indubitable y cotidiano. En tanto uno de los medios más referidos por los habitantes a partir del cual el püllü se manifiesta es el pewma:
En su descanso le digo que no lo olvido, que estoy prendiendo velas. Le digo que cuide a su hijo, que ande bien, porque ahora su hijo se fue para afuera [ciudad de Santiago]. Le digo que lo cuide, ya que él lo dejó solo, que lo cuide, que no ande metido en esas drogas y cuestiones. Y él, cuando yo no voy al cementerio o no le prendo velas en su descanso, viene a pedirme comida. Me dice que tiene hambre, si no queda comida en la olla, me lo dice en sueños. Yo esos sueños los tengo bien claros, cuando no voy al cementerio o ahí a su descanso él viene en la noche, suele andar por allá afuera. Porque él me dice 'mami tengo hambre, no te quedó comida, quiero comida'. O ‘quiero cigarro', porque era fumador. Entonces yo le prendo velas y le pongo un cigarrito prendido encimita de algo ahí en su descanso. Pero él viene, él nunca se olvida de mí. A veces yo me olvido de él, pero él no se olvida (Rosa V.).

El árbol devenido en descanso, tal como se colige de los dos puntos expuestos, rebasa el carácter de señal y/o espacio recordatorio. Ya sea como espacio de vinculación entre humanos, y entre humanos y no humanos o como principal y cotidiano espacio de manifestación de los antepasados, evidencia un cambio en su estatuto ontológico. Y al devenir en descanso, el árbol, a su vez, deviene en morada del püllü y de los distintos püllü que, eventualmente, se hospedarán en su materialidad. Igualmente, el estatuto de morada que alcanza el árbol marca la finalización de los funerales de un difunto, por cuanto constata el regreso de su püllü al colectivo desde el cual migró, no obstante, ubicado en el plano de los antepasados.

\section{Conclusiones}

Los funerales en el área mapuche cordillerana se efectúan con el propósito de insertar correctamente a los difuntos al plano de los antepasados y, con ello, convertirlos en uno de ellos. El descanso es un rito dentro de los funerales en donde se lleva a cabo la "muda ontológica" del püllü de los difuntos; es la instancia primera -en el marco del proceso mortuorio- en donde se separa al püllü de los difuntos respecto del espacio de los humanos y, a su vez, se lo relaciona con los alwe o ancestros. 
El mecanismo principal donde el rito produce la muda es doble. Por una parte, mediante el discurso exhortativo del amulpüllün se le expulsa del plano de los humanos. Por otra, con la ofrenda de un kare kare (gallina ritual) se lo vincula con el plano de los alwe o ancestros.

El lugar escogido para desarrollar el rito se elige con antelación. Corresponde a un sitio ubicado en los límites del terreno en donde se encuentra la casa del difunto, en donde se erija un árbol $\mathrm{y}$, además, que haya sido del gusto del difunto mientras vivía. Igualmente, se escogen aquellos lugares en donde ya se encuentre emplazado un descanso. Otros aspectos se le suman en el marco del rito: una cruz y/o una pequeña vivienda similar a las animitas, igualmente denominadas descanso. Estas materialidades sirven de habitáculo al püllï del difunto una vez que regresa. Sin embargo, el transcurso del tiempo le va otorgando legitimidad al árbol contiguo. Como resultado, una vez carcomidas las materialidades construidas, el árbol -no siendo ya necesaria ningún tipo de reconstrucción a la cruz y/o pequeña vivienda apostada a sus pies-deviene en descanso y, por tanto, se transforma en la morada del püllü del difunto.

El estatuto ontológico del árbol devenido en descanso rebasa la mera señal o el liso y llano espacio recordatorio. El carácter de las interacciones cotidianas de los humanos respecto de él revelan el estatuto que posee en el marco del colectivo local. Los cultos colectivos y personales que suscita y el existir in- corporado por un püllü que se relaciona asiduamente con los humanos por medio del pewma (sueño), son prácticas y eventos que sitúan al árbol del descanso como morada del püllü del difunto a cuyos pies se celebra el rito homónimo. Este, además, alcanza el estatuto de sujeto, al igual que otras entidades -che (humanos), ngen (espíritus de la naturaleza silvestre), Ngenechen (principal deidad celestial), wingkul (cerros), pillan (volcán)- que habitan el colectivo desde el que migra, y al cual regresa transmutado en ancestro.

Por último, la perspectiva de corte ontológico respecto del descanso -al iluminar la presencia crucial de los antepasados en el ritual y la cotidianidad-, junto con propiciar una mirada crítica a los estudios rituales mediante la intrusión de sujetos no humanos mapuche en el análisis, invita a matizar y complejizar ciertas aseveraciones basadas en trabajos etnográficos recientes ${ }^{40}$. De tal modo, frente a la conjetural intrascendencia de los antepasados en el mundo mapuche (Course 2008, 2011; Di Giminiani 2012), sigue resonando el eco de "la pregunta retórica" (Faron 1997 [1964]:9) que se les hace a sus espíritus: ‘¿Has pasado a convertir al árbol en tu morada?'

Agradecimientos: al Fondo Nacional de Desarrollo Científico y Tecnológico por medio del Proyecto 1120139: "La Impronta Andina en el Sistema Religioso Cosmovisionario Mapuche Williche" y al Consejo Nacional de la Cultura y las Artes Los Ríos mediante el Proyecto Fondart Regional 89426: "El descanso, un rito fúnebre mapuche", pues han hecho posible la elaboración de este artículo; a las personas de las comunidades mapuche consignadas que participaron y colaboraron en este estudio; al equipo de investigadores del proyecto Fondecyt 1090465: "Los Paisajes del Agua", especialmente a Juan C. Skewes y María E. Solari, por el crucial apoyo en los primeros pasos de la investigación; a los tres evaluadores anónimos, pues sus inteligentes sugerencias e incisivas críticas aportaron a mejorar variados aspectos del escrito. El autor dedica este artículo a María Uberlinda Calfuluán ("Doña Ube"), René Jaramillo y Anselmo Jaramillo ("Don Fidel"), cuyo cariño y orgullo por su tuwün o lugar de origen siguen reluciendo intactos en sus respectivos árboles-descansos.

\section{Referencias Citadas}

Aguilera, P. 1991. En la Frontera Vida/Muerte. Problemas Bioéticos. Editorial Universitaria, Santiago.

Alonqueo, M. 1979. Instituciones Religiosas del Pueblo Mapuche. Ediciones Nueva Universidad, Santiago.

Alvarado, M. 2000. Vida, muerte y paisaje en los bosques templados. Un acercamiento a la estética del paisaje en la Región del Calafquén. Aisthesis 33:198-216.
Alvarado, M. y R. Mera 2004. Estética del paisaje y reconstrucción arqueológica. El Caso de la región del Calafquén (IX y X RegiónChile). Chungara Revista de Antropología Chilena, Volumen Especial, Tomo II, pp. 559-568.

Århem, Kaj. 1993. Ecosofía Makuna. En La Selva Humanizada: Ecología Alternativa en la Selva Húmeda del Trópico Colombiano, editado por F. Correa, pp. 105-122. Instituto Colombiano de Antropología, Bogotá. 
Augusta, F. 1903. Gramática Araucana. Imprenta Central J. Lampert, Valdivia.

Baca, J. 2015. Liberating Forestry: Forestry Workers, Participatory Politics, and the Chilean Nation. Doctoral Dissertation, Department of Geography, University of California, Berkeley.

Bacigalupo, A. 2001. La Voz del Kultrún en la Modernidad. Tradición y Cambio en la Terapéutica de Siete Machi. Editorial Universidad Católica de Chile, Santiago.

Bacigalupo, A. 2007. Shamans of the Foye Tree: Gender, Power, and Healing Among Chilean Mapuche. University of Texas Press, Austin.

Bacigalupo, A. 2008-2009. Vida, muerte y renacimiento de una machi mapuche. Recordar, desrecordar y la transformación deliberada de una memoria. Historia Indígena 11:7-31.

Barfield, T. 2001 [1997]. Diccionario de Antropología. Traducido por C. Sánchez-Rodrigo. Edicions Bellaterra, Barcelona.

Barreto, O. 1996. Fenomenología de la Religiosidad Mapuche. Editorial Abya-Yala, Quito.

Barrientos, C. 2003. Y las enormes trilladoras vinieron (...) a llevarse la calma. Neltume, Liquiñe, Chihuío, tres escenarios de la construcción cultural de la memoria en el sur de Chile. En Luchas Locales, Comunidades e Identidades, editado por E. Jelin y P. del Pino, pp. 107-144. Siglo XXI, Madrid.

Bessire, L. y D. Bond 2014. Ontological anthropology and the deferral of critique. American Ethnologist 41:440-456.

Bize, C. 2012. Historia y memoria. Hacia una experiencia de poder popular: los trabajadores de la madera en la cordillera de Valdivia (Neltume 1970-1971). En Memoria, Historia y Derechos Humanos, editado por I. Piper y B. Rojas, pp. 15-36. Domeyko Sociedad y Equidad, Santiago.

Blaser, M. y M. De la Cadena 2009. Introducción. Ram-Wan 4:3-9.

Bloch, M. 1986. From Blessing to Violence: History and Ideology in the Circumcision Ritual of the Merina of Madagascar. Cambridge University Press, Cambridge.

Bonelli, C. 2012. Ontological disorders: Nightmares, psychotropics drugs and evil spirits in southern Chile. Anthropological Theory 12:407-426.

Bonelli, C. 2014. What Pehuenche blood does. Hemic feasting, intersubjetive participation, and witchcraft in Southern Chile. HAU: Journal of Ethnographic Theory 4:105-127.

Bravo, J. 2011. De Carranco a Carrán: Las Tomas que Cambiaron la Historia. LOM, Santiago.

Calvo, M. 1990 [1968]. Secretos y Tradiciones Mapuches. Editorial Andrés Bello, Santiago.

Campos, E. (dir.) 2012. Neltume 81'. Universidad de Chile, Santiago.

Caniguan, N. y F. Villarroel 2011. Muñkupe Ülkatun. Que el Canto Llegue a Todas Partes. LOM, Santiago.

Cañas, A. 1910. Estudios de la Lengua Veliche. Imprenta Barcelona, Santiago.

Carmona, R. 2014. Mapuche Urbanos y Gobierno Local. Etnografía de la Oficina de Asuntos Indígenas de la Comuna de la Pintana. Tesis para optar al grado de Magíster en Antropología, Escuela de Antropología, Universidad Academia de Humanismo Cristiano, Santiago.

Carrasco, H. 1986. El mito del sumpall en la cultura mapuche o araucana de Chile. Revista Chilena de Humanidades 8:49-68.

Citarella, L. 2000 [1995]. Medicinas y Culturas en la Araucanía. Editorial Sudamericana, Santiago.

Comité de Defensa de los Derechos del Pueblo (CODEPU) 1991. Chile: Recuerdos de la Guerra. Valdivia- Neltume- ChihuioLiquiñe. Colección Verdad y Justicia $\mathrm{N}^{\circ} 2$. Emisión, Valdivia.

Comité Memoria Neltume (CMN) 2013 [2003]. Guerrilla en Neltume. Una Historia de Lucha y Resistencia en el sur Chileno. LOM, Santiago.

Coña, P. 1971 [1930]. Memorias de un Cacique Mapuche. ICIRA, Santiago.

Costa, L. y C. Fausto 2010. The return of the animists. Recent studies of Amazonian ontologies. Religion and Society: Advances in Research 1:89-109.

Course, M. 2007. Death, biography and the mapuche person. Ethnos 72:77-101.

Course, M. 2008. Mapuche ñi Mongen: Individuo y Sociedad en la Vida Mapuche Rural (libro sin publicar). Traducido por M. González. Instituto de Estudios Indígenas Universidad de la Frontera, Temuco.

Course, M. 2010. Of words and fog. Linguistic relativity and Amerindian ontology. Anthropological Theory 10:247-263.

Course, M. 2011. Becoming Mapuche: Person and Ritual in Indigeous Chile. University of Illinois Press, Urbana.

Crapanzano, V. 1981. Rite of return: Circumcision in Morocco. En The Psychoanalytic Study of Society 9, editado por W. Muensterberger y L. B. Boyer, pp. 15-36. Psychohistory Press, New York.

Cruikshank, J. 2005. Do Glaciers Listen? Local Knowledge, Colonial Encounters and Social Imagination. University of British Columbia Press, Vancouver.

Curaqueo, D. 1989-1990. Creencias religiosas mapuche. Revisión crítica de interpretaciones vigentes. Revista Chilena de Antropología 8:27-33.

DaMatta, R. 2000. Individualidade e liminaridade: Considerações sobre os ritos de passagem e a modernidade. Mana 6:7-29.

De France, C. 1982. Cinemá et Anthropologie. Editions de le Maison des Sciences de L'Homme, Paris.

De La Maza, F. 2007. Política Social Para Indígenas. Un Análisis Desde la Construcción del Estado y la Interacción Local, Panguipulli (1990-2005), Chile. Tesis para optar al grado de Doctora en Antropología, Centro de Investigaciones y Estudios Superiores en Antropología Social (CIESAS), México D.F.

De Ovalle, A. 2003 [1646]. Historica Relacion del Reino de Chile, y de las Misiones y Ministerios que Ejercita en él la Compañía de Jesús. Pehuén, Santiago.

Descola, P. 2005 [1993]. Las Lanzas del Crepúsculo. Relatos Jíbaros, Alta Amazonía. Traducido por V. Castelló- Jobert y R. Ibarlucía. Fondo de Cultura Económica, Buenos Aires. 
Descola, P. 2012 [2005]. Más Allá de Naturaleza y Cultura. Traducido por H. Pons. Amorrortu, Buenos Aires.

Díaz, A. 2006 [1907]. Parlamento de Coz Coz. Ser Indígena Ediciones, Valdivia.

Di Giminiani, P. 2012. Tierras Ancestrales, Disputas Contemporáneas. Pertenencia y Demandas Territoriales en la Sociedad Mapuche Rural. Ediciones Universidad Católica de Chile, Santiago.

Di Giminiani, P. 2013. The contested rewe: sacred sites, misunderstandings and ontological pluralism in Mapuche land negotiations. Journal of the Royal Anthropological Institute 19:527-544.

Dillehay, T. 2007. Monuments, Empire and Resistance. The Araucanian Polity and Ritual Narratives. Cambridge University Press, Cambridge.

Duath, J. 1978. Evolución de la Industria en el Complejo Forestal y Maderero Panguipulli. Memoria para optar al título de Profesor General de Educación Básica, Escuela de Educación, Pontificia Universidad Católica de Chile, Villarrica.

Durkheim, E. 2012 [1912]. Las Formas Elementales de la Vida Religiosa: El Sistema Totémico en Australia. Traducido por J. Ruiz Rivas. Fondo de Cultura Económica, México D.F.

Escobar, A. 2012. Cultura y diferencia: La ontología política del campo de cultura y desarrollo. Wale'keru. Revista de Investigación en Cultura y Desarrollo 2:7-16.

Escobar, A. 2014. Sentipensar con la Tierra. Nuevas Lecturas Sobre Desarrollo, Territorio y Diferencia. Ediciones UNAULA, Medellín.

Evans-Pritchard, E. 1976 [1937]. Brujería, Magia y Oráculos entre los Azande. Traducido por A. Desmonts. Anagrama, Barcelona.

Faron, L. 1997 [1964]. Antupaiñamko. Moral y Ritual Mapuche. Traducido por P. Mege. Editorial Nuevo Extremo, Santiago.

Febrés, A. 1975 [1765]. Arte de la Lengua del Reyno de Chile. Cabildo, Vaduz-Georgetown.

Foerster, R. 1985. Vida Religiosa de los Huilliches de San Juan de la Costa. Ediciones Rehue, Santiago.

Foerster, R. 1992. Los mapuches y su religión. En Religiones Amerindias. 500 Años Después (tomo II), compilado por J. Bottaso, pp. 5-97. Editorial Abya-Yala, Quito.

Foerster, R. 1993. Introducción a la Religiosidad Mapuche. Editorial Universitaria, Santiago.

Foucault, M. 1999 [1969]. ¿Qué es un autor? http://www. saber.ula.ve/bitstream/123456789/15927/1/davila-autor.pdf (30 diciembre 2015).

Fournier, P., C. Mondragón y W. Wiesheu (coord.) 2009. Ritos de Paso. Arqueología y Antropología de las Religiones (Vol. III). Instituto Nacional de Antropología e Historia, México D.F.

Gay, C. 1998 [1844]. Ceremonia del entierro del cacique Cathiji en la Araucanía. En Etnografía Mapuche del Siglo XIX, editado por I. Inostroza, pp. 19-26. Ediciones de la Dirección de Bibliotecas, Archivos y Museos, Santiago.

Gay, C. 2010 [1854]. Atlas de la Historia Física y Política de Chile (tomos I y II). LOM, Santiago.
Geertz, C. 2005 [1973]. La Interpretación de las Culturas. Traducción de C. Reynoso. Barcelona, Gedisa.

Gissi, N. 1997. Aproximación al Conocimiento de la Memoria Mapuche Williche de San Juan de la Costa. Tesis para optar al título de antropólogo. Departamento de Antropología, Universidad de Chile, Santiago.

Godelier, M. 2004. Métamorphoses de la Parenté. Fayard, Paris. González G., M. 2015. The truth of experience and its communication: Reflections on mapuche epistemology. Anthropological Theory 15:141-157.

González, S. 2015. Antropología y el estudio de las ontologías a principios del siglo XXI: sus problemáticas y desafíos para el estudio de la cultura. Estudios Sobre las Culturas Contemporáneas 42:39-64.

Grebe, M. 1986. Algunos paralelismos en los sistemas de creencias mapuches: los espíritus del agua y de la montaña. Cultura, Hombre, Sociedad 3:143-154.

Grebe, M. 1992. El concepto de ngen en la cultura mapuche. Lengua y Literatura Mapuche 5:1-7.

Grebe, M. 1993-1994. El subsistema de los ngen en la religiosidad mapuche. Revista Chilena de Antropología 12:45-64.

Guarini, C. 1991. Cine y Antropología. De la observación directa a la observación diferida. En El Salvaje Metropolitano. Reconstrucción del Conocimiento Social en el Trabajo de Campo, compilado por R. Guber, pp. 113-128. Editorial Legasa, Buenos Aires.

Guasch, O. 2002 [1997]. Observación Participante. Centro de Investigaciones Sociológicas, Madrid.

Guerra, D. y J. Skewes 2013. Infiltraciones: las aguas y el materialismo vital a orillas del lago Neltume, Región de los Ríos, Chile. Actas VII Congreso Chileno de Antropología, pp. 437-453. Colegio de Antropólogos de Chile, Santiago.

Guevara, T. 1913. Las Últimas Familias y Costumbres Araucanas. Imprenta Barcelona, Santiago.

Gusinde, M. 1982 [1931]. Los Indios de Tierra del Fuego. Centro Argentino de Etnología Americana, Buenos Aires.

Hallowell, I. 1960. Ojibwa ontology, behavior, and world view. En Culture in History: Essays in Honor of Paul Radin, editado por S. Diamond, pp. 15-52. Columbia University Press, New York.

Havestadt, B. 1777. Chilidúgu. Sive Tractatus Linguae Chilensis. Typis, Teubneri.

Henare, A., M. Holbraad y S. Wastell (eds.) 2007. Thinking Through Things: Theorising Artefacts Ethnographically. Routledge, London.

Hertz, R. 1990 [1907]. Contribución a un estudio sobre la representación colectiva de la muerte. En La Muerte y la Mano Derecha. Compilado por R. Rubio, pp. 13-88. Traducido por R. Rubio. Alianza Editorial, Madrid.

Hilger, I. 1957. Araucanian Childlife and its Cultural Background. Smithsonian Miscellaneous Collections, Washington D.C.

Hirt, I. 2012. Mapping dreams/dreaming maps: Bridging indigenous and western geographical knowledge. Cartographica 2012:105-120. 
Holbraad, M. 2010. 'Ontology' is just another word for 'culture'. Against the motion. Critique of Anthropology 30:179-185.

Holbraad, M. 2014. Tres provocaciones ontológicas. Ankulegi 18:127-139.

Ingold, T. 2000. The Perception of the Environment: Essays on Livelihood, Dwelling and Skill. Routledge, London.

Ingold, T. 2011. Being Alive. Essays on Movement, Knowledge and Description. Routledge, London.

Jara, R., H. Gaete, M. Inostroza y R. Salinas 1980. Estudio Descriptivo de Cuatro Comunidades Cercanas al Lago Calafquén. Tesis para optar al título de Profesor de Educación Básica, Facultad de Letras y Educación, Universidad Austral de Chile, Valdivia.

Koessler, B. 2006 [1962]. Cuenta el Pueblo Mapuche. Volumen I. Tradiciones. Editorial Marenostrum, Santiago.

Kohn, E. 2013. How Forests Think. Toward and Anthropology Beyond the Human. University of California Press, Berkeley.

Kuramochi, Y. y J. Nass 1989. Valoración de la tradición y causalidad. Actas de Lengua y Literatura Mapuche 3:27-56.

Kuramochi, Y. y R. Huisca 1997. Cultura Mapuche. Editorial Abya-Yala, Quito.

Kuramochi, Y. y J. Nass 1991. Mitología Mapuche. Editorial Abya-Yala, Quito.

Latcham, R. 1924. La Organización Social y las Creencias Religiosas de los Antiguos Araucanos. Imprenta Cervantes, Santiago.

Latour, B. 2007 [1991]. Nunca Fuimos Modernos. Ensayo de Antropología Simétrica. Traducido por V. Goldstein. Siglo XXI, Buenos Aires.

Latour, B. 2008 [2005]. Reensamblar lo Social. Una Introducción a la Teoría del Actor-Red. Traducido por G. Zadunaisky. Ediciones Manantial, Buenos Aires.

Latour, B. 2013 [2012]. Investigación Sobre los Modos de Existencia. Una Antropología de los Modernos. Traducido por A. Bixio. Paidós, Buenos Aires.

Le- Bert, A. 2011. Economía Campesina en el Pueblo de Nirivilo. Informe Cátedra Antropología Aplicada: Antropología Rural 1, Departamento de Antropología, Universidad de Chile, Santiago.

Le Bonniec, F. 2013. La participación de las comunidades mapuche-huilliche en el proceso de Reforma Agraria en la provincia de Valdivia (1970-1973). Revista Austral de Ciencia Sociales 24:27-43.

Leenhardt, M. 1997 [1947]. Do Kamo. La Persona y el Mito en el Mundo Melanesio. Traducido por M. Marmora y S. Saavedra. Paidós, Barcelona.

Mancilla, N. 2012. Lago Neltume: Saberes, Complejidad Ambiental y Tensiones de Racionalidad. Desde la Interculturalidad a los Espacios de Comunicación en un Conflicto Socioambiental. Tesis para optar al título de periodista, Instituto de Comunicación Social, Universidad Austral de Chile, Valdivia.

Mancilla, N., C. Aguilar y V. Valenzuela 2012. Reflote de wampo: el reflote de los significados mapuche como práctica resistente. Perspectivas de la Comunicación 5:23-36.
Manquilef, M. 1911. Comentarios del pueblo araucano (la faz social). Revista de Folklore Chileno. Entrega Primera. Tomo II. Imprenta Cervantes, Santiago.

Martínez, B. 2014. La liminalidad revisitada: ciclos y sucesiones en El Cajón (Catamarca, Argentina). Sociedad y Religión 42:12-33.

Mellado, M. 2014. ¡Eran Raíces! Relaciones Sociales en las Huertas Familiares Mapunche del Lago Neltume, Panguipulli. Tesis para optar al título de antropóloga, Instituto de Estudios Antropológicos, Universidad Austral de Chile, Valdivia.

Millanguir, D. 2007. Panguipulli. Historia y Territorio (18501946). Imprenta Austral, Valdivia.

Mondragón, C. 2009. Encarnando a los espíritus en la Melanesia: la innovación como continuidad en el norte de Vanuatu. En Ritos de Paso. Arqueología y Antropología de las Religiones (Vol. III) coordinado por P. Fournier, C. Mondragón y W. Wiesheu, pp. 121-149. Instituto Nacional de Antropología e Historia, México D.F.

Montecino, S. 1997. El río de las lágrimas. Revista Anales de la Universidad de Chile 6:1-17.

Moulian, R. (dir.) 2008. Ngen rupu/El Camino del Ngen. Universidad Austral de Chile \& Consejo Nacional de la Cultura y las Artes, Valdivia.

Moulian, R. 2012. Metamorfosis Ritual: Desde el Nguillatun al Culto Pentecostal. Ediciones Kultrún, Valdivia.

Moulian, R. y P. Espinoza 2014. Pneumatolgía, paisaje y culto: Patrones andinos en los procesos de ancestralización de la cultura mapuche williche emplazados en la naturaleza. Chungara Revista de Antropología Chilena 46: 637-650.

Murray, M., S. Bowen, N. Segura y M. Verdugo 2015. Apprehending volition in early socialization: Raising "little persons" among rural mapuche families. Ethos 43:376-401.

Nakashima, L. 1989. Dream Interpretation Among the Mapuche Indians of Chile. Doctoral Dissertation, Department of Anthropology, University of California, Los Angeles.

Nakashima, L. 1992. Sueños de muerte y de transformación de los mapuche de Chile. En La Muerte y el Más Allá en las Culturas Indígenas Latinoamericanas, compilado por M. Cipolletti y E. Langdon, pp. 37-51. Ediciones Abya-Yala, Quito.

Pérez, P. y R. Lucena 2000. Duelo: una perspectiva transcultural. Más allá del rito: la construcción social del sentimiento del dolor. Psiquiatría Pública 12:259-271.

Plath, O. 1993. L'Animita: Hagiografía Folklórica. Editorial Pluma y Pincel, Santiago.

Ramos, A. 2008. El nawel y el pillañ. La relacionalidad, el conocimiento histórico y la política mapuche. Ram- Wan 4:57-79.

Ramos, A. 2010. Los Pliegues del Linaje. Memorias y Políticas Mapuche-Tehuelche en Contextos de Desplazamiento. Eudeba, Buenos Aires.

Reynoso, C. 2014. Crítica de la Antropología Perspectivista. Viveiros de Castro, Philippe Descola, Bruno Latour. Ediciones $\mathrm{SB}$, Buenos Aires.

Rivas, R. 2006. Desarrollo Forestal de Neltume: Estado y Trabajadores (1924-1990). Tesis para optar al título de 
Profesor de Historia, Geografía y Educación Cívica, y al grado de Licenciado en Historia, Instituto de Ciencias Sociales, Universidad Austral de Chile, Valdivia.

Rojas, P. 2012. El descanso, un rito fúnebre mapuche. De la transubstanciación de persona a paisaje en la precordillera del centro sur de Chile. En Naturaleza y Cultura en América Latina. Escenario para un Modelo de Desarrollo no Civilizatorio, compilado por E. Alfaro, K. Enríquez y Y. Flores, pp. 149-165. Editorial Abya-Yala \& Universidad Politécnica Salesiana, Quito.

Rojas, P. (dir.) 2013. Persona/Paisaje. El descanso, un rito fúnebre mapuche. Proyecto Fondecyt 1090465 \& Coordinación de Extensión Facultad de Filosofía y Humanidades de la Universidad Austral de Chile, Valdivia.

Rojas, P., J. Skewes y M. Poblete 2011. Los descansos de Lago Neltume: Imágenes de los hitos funerarios del mundo mapuche cordillerano. Revista Chilena de Antropología Visual 17:124-145.

Rojas, P., M. Mellado y C. Morales 2015. La cámara en el trabajo de campo: usos éticos y metodológicos del registro audiovisual en el mundo mapuche cordillerano. Revista Chilena de Antropología Visual 26:138-156.

Sautu, R., P. Boniolo, P. Dalle y R. Elbert 2005. Manual de Metodología. Construcción del Marco Teórico, Formulación de los Objetivos y Elección de la Metodología. CLACSO, Buenos Aires.

Sahlins, M. 2011 [2008]. La Ilusión Occidental de la Naturaleza Humana. Traducido por L. Andrade. Fondo de Cultura Económica, México D. F.

Schindler, H. 1996. Amulpüllün: Un rito funerario de los mapuche chilenos. Lengua y Literatura Mapuche 7:165-180.

Schindler, H. y M. Schindler 2006. La Piedra Santa de Lumaco. En Cuatro Estudios Acerca de la Espiritualidad Mapuche, editado por H. Schindler, pp. 11-67. Verlagsbuchhandlung, Munchen.

Skewes, J. y D. Guerra 2011. Contra-mercantilizar, aguzar los sentidos y conversar con los árboles: indicaciones mapuche contemporáneas para una frágil emancipación. Revista Márgenes: Espacio, Arte, Sociedad 8-9:72-81.

Skewes, J. y D. Guerra 2015. Sobre árboles y personas: la presencia del roble (Nothofagus obliqua) en la vida cordillerana mapuche de la cuenca del río Valdivia. Atenea 512:189-210.

Skewes, J., D. Guerra y C. Henríquez 2014. Patrimonio y paisaje: dos formas de ensamblar naturaleza y cultura en la cuenca del río Valdivia, sur de Chile. Chungara Revista de Antropología Chilena 46:651-668.

Skewes, J., D. Guerra, P. Rojas y M. Mellado 2011. ¿La memoria de los paisajes o los paisajes de la memoria? Los enigmas de la sustentabilidad socioambiental en las geografías en disputa. Desemvolvimento e Meio Ambiente 23:39-57.

Skewes, J., P. Poblete, P. Rojas y M. Mellado 2011. Animitas y descansos en los paisajes culturales mapuche y chilenos: La articulación de lo cotidiano y lo sagrado a orillas del lago Neltume. Ponencia presentada en Coloquio Lecturas de la Animita. Estética, Identidad y Patrimonio, Santiago.

Smith, E. 1914 [1855]. Los Araucanos o Notas Sobre una Gira Efectuada Entre las Tribus Indígenas de Chile Meridional. Traducido por R. Latcham. Imprenta Universitaria, Santiago.
Smith, W. 1956 [1889]. The Religion of the Semites. The Fundamental Institutions. The Meridian Library, New York.

Sociedad Chilena de Lingüística 1988. Alfabeto Mapuche Unificado. Universidad Católica de Chile, Temuco.

Strathern, M. 1988. The Gender of the Gift: Problems with Womens and Problems whit Society in Melanesia. California University Press, Berkeley.

Stuchlik, M. 1999 [1976]. La Vida en Mediería: Mecanismos de Reclutamiento Social de los Mapuches. Traducido por F. Salinas. Soles, Santiago.

Taylor S. y R. Bogdan 1994 [1984]. Introducción a los Métodos Cualitativos de Investigación. Traducido por J. Piatigorsky. Paidós, Barcelona.

Titiev, M. 1951. Araucanian Culture in Transition. Michigan University Press, Michigan.

Tola, F. 2012. Yo no Estoy Solo en mi Cuerpo. CuerposPersonas Múltiples Entre los Toba del Chaco Argentino. Biblios/Culturalia, Buenos Aires.

Turnbull, D. 2000. Masons, Tricksters and Cartographers: Comparative Studies in the Sociology of Scientific and Indigenous Knowledge. Routledge, New York.

Turner, V. 1974. Dramas, Fields and Metaphors. Ithaca, New York.

Turner, V. 1988 [1969]. El Proceso Ritual. Estructura y Antiestructura. Traducido por B. García Ríos. Taurus, Madrid.

Turner, V. 1999 [1967]. La Selva de los Símbolos. Aspectos del Ritual Ndembu. Traducido por R. Valdés del Toro y A. Cardín Garay. Siglo XXI, Madrid.

Turner, V. y E. Turner 1978. Image and Pilgrimage in Christian Culture. Columbia University Press, New York.

Valdivia, L. 1887 [1606]. Arte y Gramatica General de la Lengua que Corre en Todo el Reyno de Chile, con un Vocabulario y un Confessionario. Ausgabe von Platzmann, Leipzig.

Van Gennep, A. 2008 [1908]. Los Ritos de Paso. Traducido por J. Aranzadi. Alianza Editorial, Madrid.

Vela, F. 2001. Un acto metodológico básico de la investigación social: la entrevista cualitativa. En Observar, Escuchar y Comprender. Sobre la Tradición Cualitativa en la Investigación Social, compilado por M. Tarrés, pp. 63-95. FLACSO, México D.F.

Véliz, C. 1996. La Muerte Araucana o Una Modificación de la Vida. Tesis para optar al grado de Licenciada en Historia, Facultad de Historia, Geografía y Ciencia Política, Pontificia Universidad Católica de Chile, Santiago.

Vergara, Jorge y A. Mascareño1996. La propiedad y conflictos de tierras indígenas en la Provincia de Valdivia. En La Propiedad Huilliche en la Provincia de Valdivia, editado por J. Vergara, A. Mascareño y R. Foerster, pp. 13-241. CONADI, Santiago.

Vilaça, A. 2005. Chronically unstable bodies: Reflections on Amazonian corporalities. Journal of the Royal Anthropological Institute 11:445-464.

Viveiros de Castro, E. 1996. Os pronomes cosmológicos e o perspectivismo ameríndio. Mana 2:115-144. 
Viveiros de Castro, E. 2002. A Inconstancia da Alma Selvagem, e Outros Ensaios de Antropologia. Cosac Naify, Sao Paulo.

Viveiros de Castro, E. 2004. Exchanging perspectives: The transformation of objects into subjects in Amerindian ontologies. Common Knowledge 10:463-484.

Viveiros de Castro, E. 2010 [2009]. Metafísicas Caníbales. Líneas de Antropología Postestructural. Traducido por S. Mastrangelo. Katz Editores, Buenos Aires.
Wagner, R. 2010 [1975]. A Invenção da Cultura. Traducción de M. Cohelo de Souza y A. Morales. Cosac Naify, Sao Paulo.

Wagner, R. 1991. The fractal person. En Big Men and Great Men: Personifications of Power in Melanesia coordinado por M. Godelier y M. Strathern, pp. 159-173. Cambridge University Press, Cambridge.

Yanai, T. 1997. Notas sobre el pillañ: En torno a E. Böning. El concepto de pillán entre los mapuches. Scripta Ethnologica 19:151-172.

\section{Notas}

1 Se entienden en este trabajo como sinónimos los términos antepasados y ancestros. Se suscribe la definición general de Barfield (2001 [1997]:40) que los conceptualiza como aquellas "personas (y a veces criaturas puramente mitológicas) de las que desciende un individuo o un linaje según un sistema de pensar la descendencia. Más estrictamente, los ancestros son aquellos progenitores socialmente importantes cuya memoria, como individuos o grupo, ha sido preservada por los individuos, por un grupo de parentesco o por una comunidad".

2 Se utiliza el alfabeto mapuche unificado -indicado por la Sociedad Chilena de Lingüística (1988)- para escribir los términos en mapudungun, exceptuando las citas, en donde se mantiene la grafía de los respectivos autores.

3 Desde ya es preciso explicitar que, por motivos de consistencia etnográfica, se opta por nombrar a los antepasados o ancestros de la misma manera en que las personas de las zonas en donde se desplegó la investigación generalmente lo hacen. Dos son los términos de los que se valen. Por una parte, el término alwe se utiliza para nombrar a los antepasados o ancestros en plural ("los" alwe...). Por otra, el término püllü es utilizado para nombrar antepasados o ancestros específicos y singulares ("el" püllü...). Si bien esta distinción se efectuaba en la mayoría de los casos, no reviste un carácter terminante y cerrado. Es decir, igualmente, en ocasiones ocurría que los términos designados se invirtieran (de acuerdo con los respectivos referentes asociados a cada uno de los conceptos anteriormente citados). En suma, aquí se utilizará el término alwe para designar a los antepasados o ancestros, aunque -en ocasiones específicas y referido a entidades singulares, al modo de la usanza local-igualmente se utilizará el concepto de püllü. Es interesante apuntar que lo encontrado en el área de estudio respecto de la asociación del püllü a una esencia individual es referida en la literatura, tanto en trabajos de carácter recopilatorio, en donde afirma que el püllü "sigue viviendo en la eternidad representando a la persona en toda su magnitud" (Citarella 2000:106) como en abordajes etnográficos recientes, en los que se asocia "el püllü al núcleo interior único del ser" (Course 2008:212); como en las acepciones presentes en los diccionarios de mapudungun, ya sea de manera implícita (Augusta 1903:345; Febrés 1975 [1765]:305, 308 y 347; Havestadt 1777:605 y 807; Valdivia 1887 [1606]:85) o explícita, tal como Cañas cuando señala en la entrada correspondiente a "espíritu": "Pullu, s.- El ánima, el espíritu, el alma de quien ha muerto..." (Cañas
1910:312). Por último, es preciso señalar que en la literatura los antepasados son referidos igualmente como "kuifi pu trem em" (Augusta 1903:345).

4 Las referencias de carácter descriptivo corresponden a una etnografía visual (Rojas et al. 2011) y a un documental etnográfico (Rojas 2013).

5 Desde esta aproximación -basada en aportes provenientes de la ecología política y de perspectivas materialistas actuales- el árbol del descanso se ha configurado como un elemento fundamental, planteándose como un soporte rememorativo de la persona: "El recuerdo del difunto se corporiza bajo la forma del árbol junto al que se ha plantado la cruz o levantado el pequeño altar. Con el tiempo estas construcciones desaparecen y queda el árbol como el recuerdo y referencia comunitaria de aquel o aquellas a quien evoca" (Skewes, Poblete et al. 2011:10). Igualmente, como un hito señero respecto de la conformación del territorio: "Los árboles, a su vez, permitían fijar la geografía social del paisaje, de modo que cada lugareño o lugareña era capaz de identificar las diversas posiciones en el territorio sobre la base de estos referentes arbóreos: en otro tiempo es probable que hubiésemos preguntado, a la Evans-Pritchard, dime de qué árbol estamos hablando para saber de quién se trata" (Guerra y Skewes 2013:451). Para otras referencias al descanso desde este enfoque, ver Skewes y Guerra 2011; Skewes, Guerra et al. 2011; Skewes et al. 2014.

6 De aquí en más, se entiende la noción de sujeto en un sentido general, como una serie de cualidades que una entidad moviliza, asociadas a la intencionalidad de sus actos, la reflexión y, sobre todo, la capacidad de actuar efectiva y ciertamente en el mundo.

7 Como sucede generalmente con las etiquetas de pensamiento, el "giro ontológico" más que designar un corpus homogéneo y bien circunscrito, corresponde a un espacio heterogéneo de propuestas actuales con ciertos puntos en común. Si bien la intención de este trabajo no es ahondar en el citado corpus, es importante señalar que hay ciertos autores omnipresentes, constituyéndose -a partir de la fecundidad y posibilidades contenidas en sus planteamientos-en verdaderos "instauradores de discursividad" (Foucault 1999 [1969]:13) como Viveiros de Castro (1996, 2002), Descola (2012 [2005]), Wagner (2010 [1975], 1991), Latour (2007 [1991], 2013 [2012]), Strathern (1988) y, de modo tangencial, Ingold $(2000,2011)$. Para trabajos centrados exclusivamente en la presentación y exégesis del "giro ontológico", consultar Costa y Fausto (2010), Holbraad (2014) y González (2015). Aproximaciones críticas al mismo 
se pueden encontrar en Bessire y Bond (2014) y Reynoso (2014). Es preciso señalar, por último, que en el marco de la etnografía mapuche los abordajes de corte ontológico comienzan con el trabajo de Ana Ramos $(2008,2010)$ y de Magnus Course (2007, 2008, 2010, 2011); siguiendo la estela abierta por Course, las investigaciones han indagado tópicos asociados al cuerpo y la salud (Bonelli 2012), el paisaje y los conflictos de propiedad (Di Giminiani 2012, 2013), la comensalidad (Bonelli 2014), el estatuto de la experiencia individual (González, M. 2015) y las pautas de crianza (Murray et al. 2015).

8 En este marco, con objeto de captar adecuadamente las relaciones entre humanos y no humanos, es que Latour (2007 [1991], 2008 [2005]) acuña el concepto de "colectivo", sustituyéndolo por el de "sociedad", el cual se centra exclusivamente en entidades humanas. Descola (2012 [2005]:518), en tanto, plantea una fértil propuesta -desde una perspectiva etnográfica- para delimitar los colectivos, tomando como criterio principal las características que adoptan las relaciones entre los existentes en su seno (y no los habituales recortes de nacionalidad, etnia, clase, edad, género o la dicotomía rural/urbano).

9 Quizás las experiencias más complejas y remarcables en relación con la adquisición, desarrollo y aplicación del conocimiento en el mundo mapuche son las vividas por las y los machi. Acerca del particular, ver Bacigalupo (2001, 2007).

10 En la misma línea, y dando cuenta de las formas diferenciales de producir conocimiento válido dependiendo del colectivo tratado, Sahlins apunta respecto del pueblo castor de la Columbia británica: "Como herederos de John Locke, para nosotros el conocimiento proviene de la experiencia sensible de los acontecimientos del mundo físico. Para los dunneza, los acontecimientos provienen del conocimiento que se tiene de estos mediante los sueños, mitos y demás, una epistemología más platónica" (Sahlins 2011 [2008]:106).

11 Para una crítica al relativismo cultural, ver Ingold (2000); para una problematización del multiculturalismo, ver Viveiros de Castro (1996, 2010 [2009]).

12 "El concepto de cultura que propugno [...] es esencialmente semiótico. Creyendo con Max Weber que el hombre es un animal inserto en tramas de significación que él mismo ha tejido, considero que la cultura es esa urdimbre" (Geertz 2005 [1973]:20).

13 La literatura de impronta histórica relativas al área en donde se emplazan las comunidades mapuche del área de estudio se ha centrado en los procesos desarrollados principalmente por actores chilenos, entre 1964 y 1981: la Reforma Agraria (Baca 2015; Bravo 2011), el gobierno de la Unidad Popular y levantamiento del Complejo Forestal y Maderero Panguipulli (Baca 2015; Bize 2012; Bravo 2011; Duath 1978; Rivas 2006), el Golpe de Estado y despliegue de la Dictadura (Baca 2015; Barrientos 2003; Bravo 2011; CODEPU 1991) y la "Operación Retorno" protagonizada por miembros del Movimiento de Izquierda Revolucionario (Campos 2012; CMN 2013 [2003]). Los trabajos de mirada diacrónica que han incorporado de modo sustantivo a las comunidades mapuche ubicadas dentro del área de estudio, corresponden a la crónica sobre el Parlamento de Coz- Coz de Díaz Meza (2006 [1907]), la indagación respecto de la conformación de la propiedad realizado por Vergara y Mascareño (1996), la revisión sinóptica efectuada por Millanguir (2007) y el análisis de la participación de las comunidades mapuche en el marco de la Reforma Agraria llevado a cabo por Fabien Le Bonniec (2013). Actualmente, en tanto, el devenir local está signado por la presencia de funcionarios de la transnacional Endesa Enel, que buscan materializar un proyecto de generación de energía hidroeléctrica. El proyecto ha sido resistido por las comunidades del área, ya que afectaría negativamente ámbitos fundamentales de su vida, como el adecuado desarrollo del Ngillatun y la presencia de los descansos tratados en este artículo. Sobre los efectos citados, ver Skewes, Guerra et al. (2011); sobre los modos en que las comunidades han movilizado su rechazo al proyecto, ver Mancilla (2012) y Mancilla et al. (2012).

14 Las comunidades Juan Quintumán, Valeriano Cayicul y Manuel Curilef presentan una imbricación entre la -utilizando las denominaciones de De la Maza (2007:157160)- "comunidad territorial" (constituida por la entrega de Títulos de Merced a principios del siglo XX) y la "comunidad jurídica" (conformada a partir de los lineamientos de la Corporación Nacional de Desarrollo Indígena implementada mediante la Ley Indígena 19.253 de 1993). La comunidad Inalafquén -creada el 2008- aglutina a miembros de la “comunidad territorial” Juan Quintumán que se encuentran en oposición al proyecto hidroeléctrico de Endesa Enel.

15 El tiempo total de estancias amplias en terreno fue de 16 meses, cuyo detalle es el siguiente: dos meses en 2011; seis meses en 2012; un mes en 2013; dos meses en 2014 y cinco meses en 2015. Se tuvo la oportunidad de participar en cuatro funerales (tres difuntos de la comunidad Juan Quintumán y un difunto de la comunidad Inalafquén), tres Ngillatun (uno en el ngillatuwe de la comunidad Valeriano Cayicul y dos en el ngillatuwe compartido por las comunidades Juan Quintumán e Inalafquén) y tres celebraciones del Día de Todos Los Santos (en el cementerio de la comunidad Manuel Curilef).

16 Un detallado análisis del uso metodológico y ético del registro audiovisual en el marco de la investigación se encuentra en Rojas et al. (2015).

17 Por supuesto, esto se plantea como una experiencia predominante, del modo en que fue hallado en el terreno. Ello no excluye la presencia de otras experiencias (ya sea en el área de estudio indagada o en otras), incluso contrapuestas.

18 Una interpretación de los funerales mapuche distinta a la predominante de carácter hertziano -que, por cierto, se suscribe en este trabajo- se puede encontrar en Course (2007, 2011) y Di Giminiani (2012). El autor que introduce la citada interpretación dentro del corpus etnográfico mapuche es el estadounidense Faron (1997 [1964]). Cabe señalar que su trabajo sigue siendo el más relevante respecto del papel de los antepasados en el mundo mapuche.

19 "Un individuo que ha sufrido ya sea (1) la cesación irreversible de las funciones circulatorias y respiratorias o, (2) la cesación irreversible de las funciones del encéfalo completo está muerto" (Aguilera 1991:29).

20 Es interesante notar el papel crucial que poseen entidades no humanas en los ciclos vitales de los humanos en diversos colectivos (incluyendo el cristianismo occidental). Al respecto, Godelier (2004:251-324) analizó a 26 colectivos de los cinco 
continentes respecto del modo en que experimentaban el proceso de concepción de los hijos. Uno de sus principales resultados fue que en todos los casos nunca bastaba la relación entre un hombre y una mujer para concebir un hijo; siempre era necesaria la injerencia de entidades no humanas (seres de la naturaleza, antepasados, dioses, entre otros) para convertirlo en un humano completo.

21 Una detallada descripción de la fabricación de esta bebida se encuentra en Manquilef (1911:52-56).

22 En la línea de lo argumentado en el clásico "caso del granero" de los azande por Evans-Pritchard (1976 [1937]:88-89).

23 Las funerarias de la comuna se encuentran distribuidas por sectores; al área de estudio le corresponde la funeraria "Pulgar" de la ciudad de Panguipulli.

24 Solo una ruka se encuentra en el sector; en el predio del longko José Catrilaf de la comunidad Juan Quintumán. Si bien el uso de la ruka se centra en actividades asociadas al turismo, igualmente le brinda alojamiento a una amplia gama de prácticas -desde ritos de impronta ancestral hasta reuniones con funcionarios estatales-, de modo similar a lo consignado por la antropóloga-artista Rosario Antonia Carmona (2014:88-89) respecto de las ruka de la ciudad de Santiago.

25 Alimento que consiste en una masa de harina de trigo freída en grasa de animal o aceite.

26 Tanto la traducción como la escritura en mapudungun fue realizada por María Inés Quilaqueo Trafiñanco.

27 Lo cual puede sugerir un pretérito culto al sol.

28 Tanto la traducción como la escritura en mapudungun fue realizada por María Inés Quilaqueo Trafiñanco.

29 El cementerio de lago Neltume completó su capacidad en 1996, por lo cual desde esa fecha a la actualidad es utilizado exclusivamente para fines rituales.

30 Este acto lo condiciona el orden del cementerio, pues todas las tumbas están orientadas hacia el puel mapu.

31 Reformulaciones relevantes a la clásica propuesta ritual de Van Gennep -en relación con la temática de este trabajo y excluyendo las ya aludidas obras de Turner- se encuentran en Crapanzano (1981), Bloch (1986), DaMatta (2000), Fournier et al. (2009) y Martínez (2014).

32 La inspiración del término proviene del campo de la biología, en su referencia al proceso por el que pasan ciertos animales al cambiar de piel o plumas y ciertas plantas el follaje.
33 Con objeto de representar esto adecuadamente es que en el esquema del rito del descanso la línea horizontal se delineó recortada.

34 En la práctica, las personas del área no movilizaban ningún tipo de clasificación por especie a la hora de escoger un determinado árbol. Así, la gama incluyó manzanos, castaños, robles, avellanos, canelos y encinos, entre otros. Es preciso aclarar igualmente que se escoge un árbol presente de antemano en el sitio.

35 Acerca de las diferencias entre las animitas y los descansos mapuche, ver Skewes, Poblete et al. (2011). En cuanto a las diferencias entre los descansos del mundo chileno campesino (Guevara 1913:288; Le-Bert 2011:30-31; Plath 1993:12; Smith 1914 [1855]:68-69) y los descansos mapuche, estas estriban -al igual que las animitas - no en la materialidad que se construye (en los tres casos puede erigirse altares similares), sino en el lugar de emplazamiento y, de modo decisivo, en la entidad que se le asocia a esta, esto condiciona determinadas prácticas cúlticas en cada caso.

36 Este patrón de emplazamiento ya está presente en los grupos pitrén (Alvarado y Mera 2004), por lo cual se puede hablar de una verdadera "memoria del paisaje" (Skewes, Guerra et al. 2011).

37 En los sectores correspondientes al área de estudio de esta investigación no se celebra el Año Nuevo Mapuche, denominado Wetripantü o Wiñol Tripantü. No obstante, en muchos otros sectores de la comuna de Panguipulli es celebrado (como, por ejemplo, en el sector de Coihueco -aledaño al área de estudio de este trabajo-, en donde se tuvo la oportunidad de participar el año 2012).

38 Concerniente a esta ritualidad, ver Kuramochi y Nass (1989) y Moulian (2008).

39 Espacio en donde se celebra el Ngillatun, y en donde los alwe se encuentran asentados una vez que el chalilelfun ha sido correctamente ejecutado.

40 "Al contrario de lo que ocurre en las tierras altas, la connotación que tienen los antepasados como fuente de poder espiritual para ser empleada por los vivos, se encuentra ausente en la sociedad mapuche" (Di Giminiani 2012:130). "Tal vez de manera más importante, no hay elaboración con respecto al destino del alma luego que es enviada a su rumbo y consecuentemente no hay conexión entre ancestro y vitalidad" (Course 2008:215-216). 